\title{
Comparative assessment of RAMS and WRF short-term forecasts over Eastern Iberian Peninsula using various in-situ observations, remote sensing products and uncoupled land surface model datasets
}

\author{
I. Gómez ${ }^{\mathrm{a}, \mathrm{b}, *}$, V. Caselles ${ }^{\mathrm{a}}$, M.J. Estrela ${ }^{\mathrm{c}}$, J.J. Miró ${ }^{\mathrm{a}}$ \\ a Earth Physics and Thermodynamics Department, Faculty of Physics, University of Valencia, Doctor Moliner, 50, 46100 Burjassot, Valencia, Spain \\ ${ }^{\mathrm{b}}$ Environment and Earth Sciences Department, Faculty of Sciences, University of Alicante, Section 99, E-03080 Alicante, Spain \\ ${ }^{c}$ Geography Department, Faculty of Geography and History, University of Valencia, Avda. Blasco Ibáñez, 28, 46010, Valencia, Spain
}

A R T I C L E I N F O

\section{Keywords:}

RAMS

WRF

Land surface models

Numerical weather prediction/forecasting

Mesoscale modelling

Remote sensing

\begin{abstract}
A B S T R A C T
The Regional Atmospheric Modeling System (RAMS) and the Weather Research and Forecasting (WRF) mesoscale models are being used for weather and air quality studies as well as forecasting tools in Numerical Weather Prediction (NWP) systems. In the current study, we perform a comparative assessment of these models under distinct typical atmospheric conditions, classified according to the dominant wind flow and cloudiness, over Eastern Iberian Peninsula. This study is focused on the model representation of key physical processes in terms of meteorology and surface variables during a 7-days period in summer 2011. The hourly outputs produced by these two models are compared not only with observed standard surface variables, measured at different permanent weather stations located over the region of study, but also with different surface remote sensing products and uncoupled Land Surface Models (LSM) datasets. Confronting RAMS and WRF, the current study highlights relevant differences over areas near the coast when mesoscale circulations or Eastern synoptic advections are developed over the region of study. A higher moisture content is observed under these atmospheric conditions, due to the moisture transport by the sea breeze inland. In this regard, it has been found that the Eastern wind field simulated by WRF reaches inland areas and comprises a larger sea breeze extension than RAMS. This sea breeze development impacts meteorology and surface variables in locations not too close to the coast, but still affected by land-sea winds. Additionally, WRF remains more windy and moister than RAMS at night-time, while alike results are found under Western synoptic advections. The results obtained in the current paper show differences under distinct dominant atmospheric conditions, which outline further research in this field in order to achieve more general conclusions.
\end{abstract}

\section{Introduction}

Mesoscale Meterological Models (MMMs), such as the Regional Atmospheric Modeling System (RAMS) and the Weather Research and Forecasting (WRF) model, are widely used tools in a broad range of applications, such as research and operational numerical weather forecasting, parameterization physics research, driving air quality models, etc. (Gómez and Estrela, 2010). A proper representation of meteorological and surface variables is of significant importance in all these application fields. Therefore, a lot of efforts have been dedicated in the last years with the aim of evaluating and improving the forecast results of both models. For instance, different studies have been performed considering the formulation of the Planetary Boundary Layer (see e. g. Borge et al., 2008; Hu et al., 2010; Steeneveld et al., 2011; Draxl et al., 2014; Hariprasad et al., 2014; Banks and Baldasano, 2016, Banks et al., 2016; Gómez et al., 2016b; Avolio et al., 2017) or the land surface and atmosphere interactions (see e. g. Hong et al., 2009; Tolk et al., 2009; Dillon et al., 2016; Kioutsioukis et al., 2016; Lara-Fanego et al., 2016; Santanello et al., 2016; Gómez et al., 2018), among others. On the other hand, the largest discrepancies between model results and observations are typically observed for cumulus precipitation (amount, location, duration, type, etc.) (see e. g. Lompar et al., 2017; Lompar et al., 2018).

In the current study, we compare the results produced by RAMS and WRF mesoscale models over Eastern Spain and during the summer 2011, from 6 to 12 July. In order to evaluate the skill of the presented

\footnotetext{
* Corresponding author at: Earth Physics and Thermodynamics Department, Faculty of Physics, University of Valencia, Doctor Moliner, 50, 46100 Burjassot, Valencia, Spain.

E-mail address: Igor.Gomez@uv.es (I. Gómez).
} 
(a)

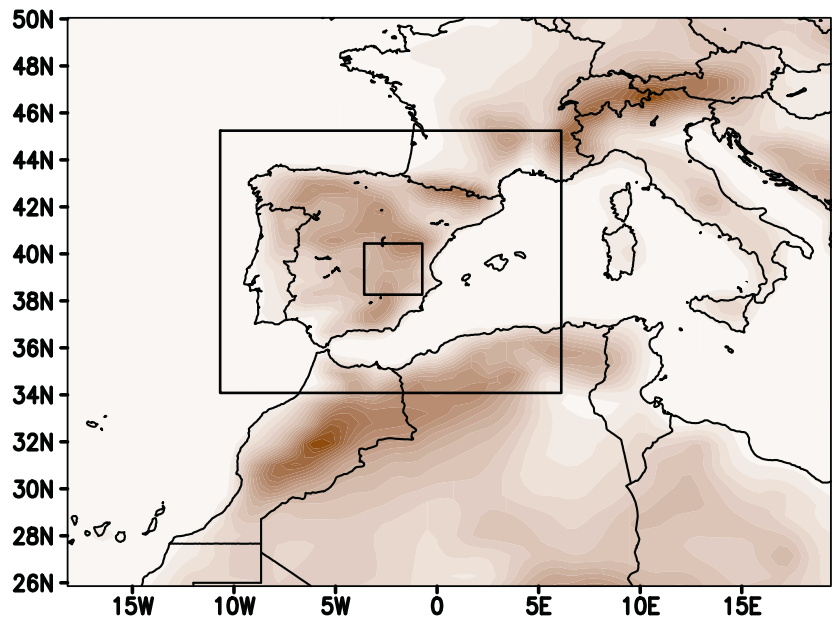

(c)

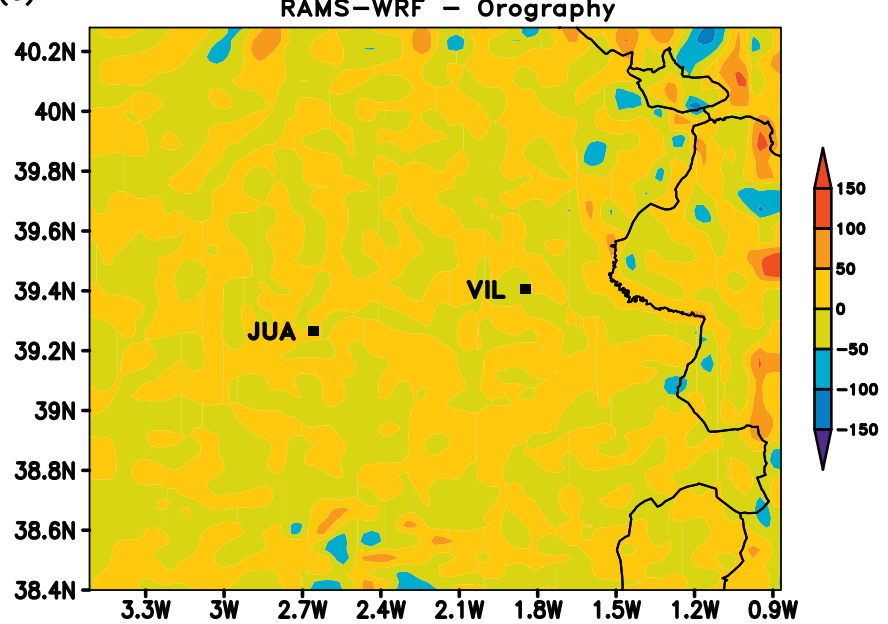

(b)

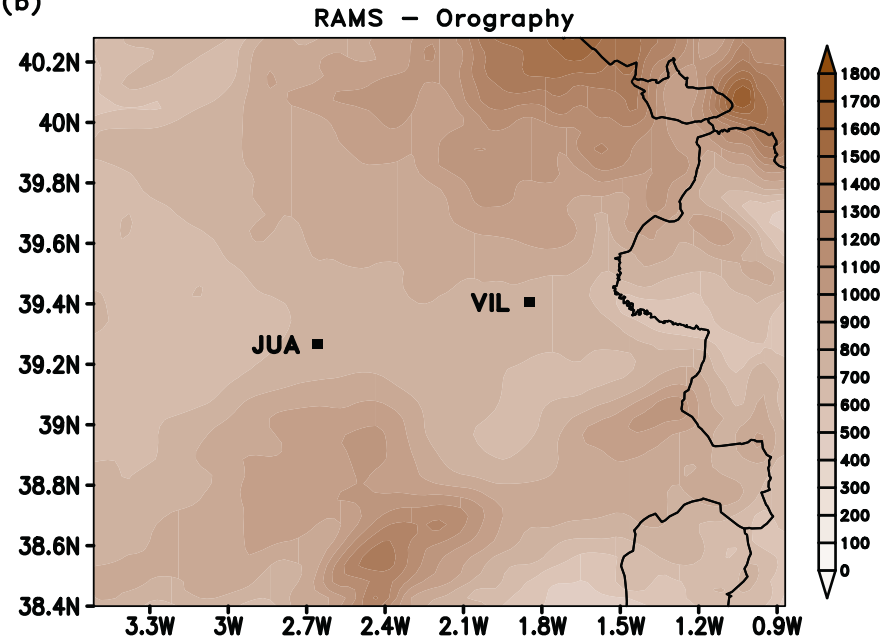

(d)

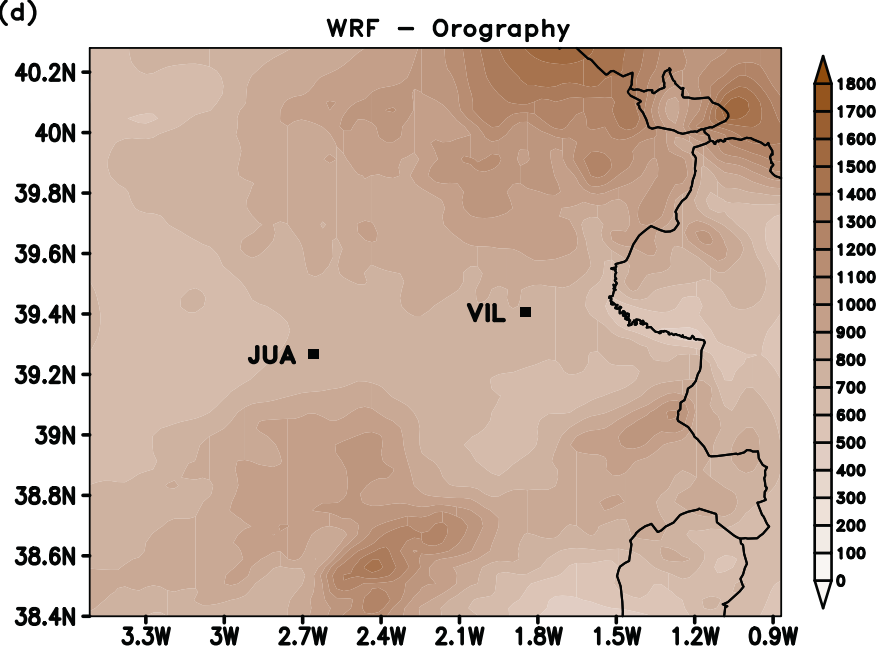

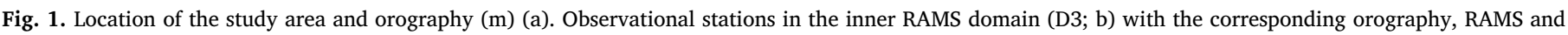
WRF orography difference (c) and WRF orography within the inner domain (d).

simulations, we use the results found in the references regarding recent studies performed using both MMMs as the base line to compare the current simulations. For instance, focusing on a key near-surface parameter in mesoscale modelling as it is the 2-m temperature, RAMS has been found to produce a warm bias in relation to the observations over the Western Mediterranean coast within the summer season (Gómez et al., 2014a, 2014b, 2014c; Gómez et al., 2015a, 2015b). In contrast, Tiriolo et al. (2015) found a cold bias at night during this season of the year, but especially during the day, using RAMS over Southern Italy. On the other hand, the verification of the 2-m temperature using WRF has been shown to produce a general cold bias during the summer season, especially considering the daytime temperatures. This result has been found in different areas, such as the United States (see e.g. Hu et al., 2010; Zhang et al., 2013), and also in Europe (see e.g. Banks and Baldasano, 2016; Banks et al., 2016; Avolio et al., 2017) or tropical areas (Xie et al., 2012). Although just highlighting here the differences in the temperature field trends, the contrast of both models is also found in other sensible surface weather parameters, such as the surface heat fluxes or the moisture field (Tolk et al., 2009; Steeneveld et al., 2011), as well as considering the wind field or the downwelling shortwave radiation (Avolio et al., 2016).

Regarding RAMS, a possible cause of the warm bias between the model and the measurements over the Western Mediterranean coast seemed to be related to the soil moisture field used in the initial conditions applied to this model. In general, soils are dry over this region, especially during the summer season. However, excessively drying deeper soil levels in RAMS leads to a substantial removal of the available latent heat flux and to a raise in the sensible heat flux, thus increasing the 2-m temperatures (Gómez et al., 2015b; Gómez et al., 2016b; Gómez et al., 2018). On the other hand, as it was suggested by Hu et al. (2010), the WRF daytime temperature biases may be caused by errors in soil moisture as well. As it will be described in the next section, both RAMS and WRF are initialized using the National Centers for Environmental Prediction (NCEP) FNL (Final) Operational Global Analysis data. In addition to the meteorological fields provided by this dataset, the soil moisture and temperature are also included in the initialization of these models. In the case of RAMS, new routines were developed to consider this feature (Gómez et al., 2016c). Additionally, previous studies have shown that using soil moisture derived from NCEP (Dillon et al., 2016) or from European Centre for Medium-Range Weather Forecasts (ECMWF) operational analysis (Kalverla et al., 2016) as input data to WRF leads to a wetter environment as well as to the above mentioned cold bias. In contrast, reducing the original soil moisture content provided by these datasets in the corresponding WRF initialization could decrease the latent heat flux, leading to an increase in the sensible heat flux as well as the near-surface temperature, producing a better agreement between the model and the observations. In order to take into account this important feature in both RAMS and 
(a)

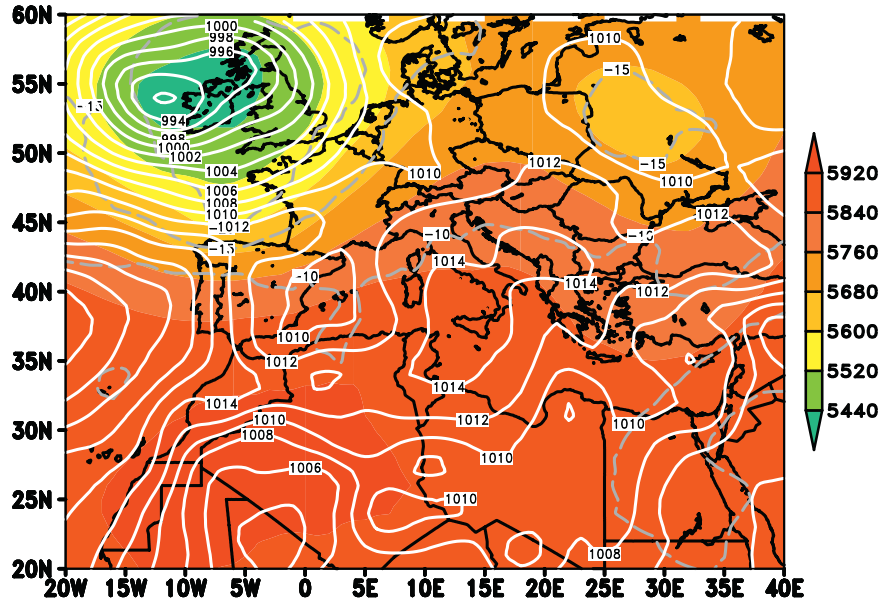

(c)

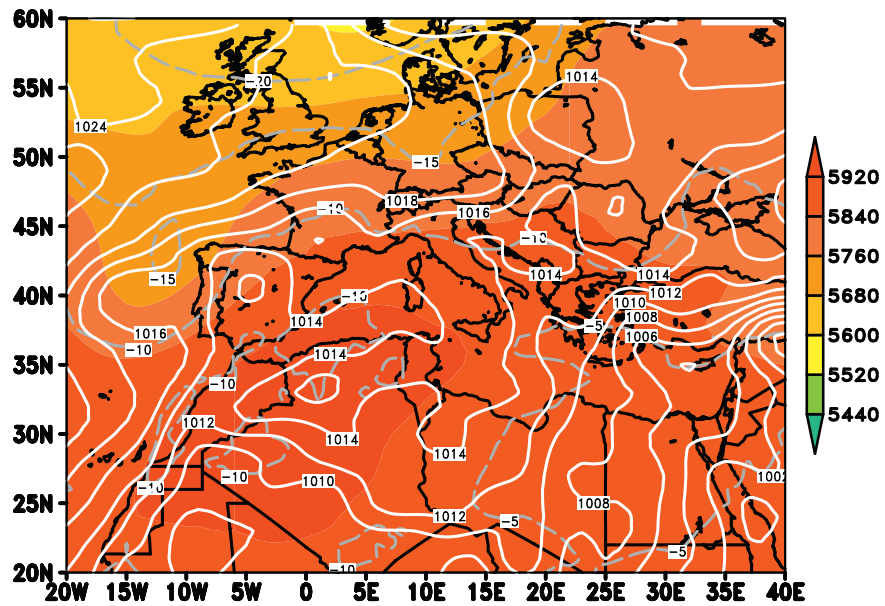

(b)

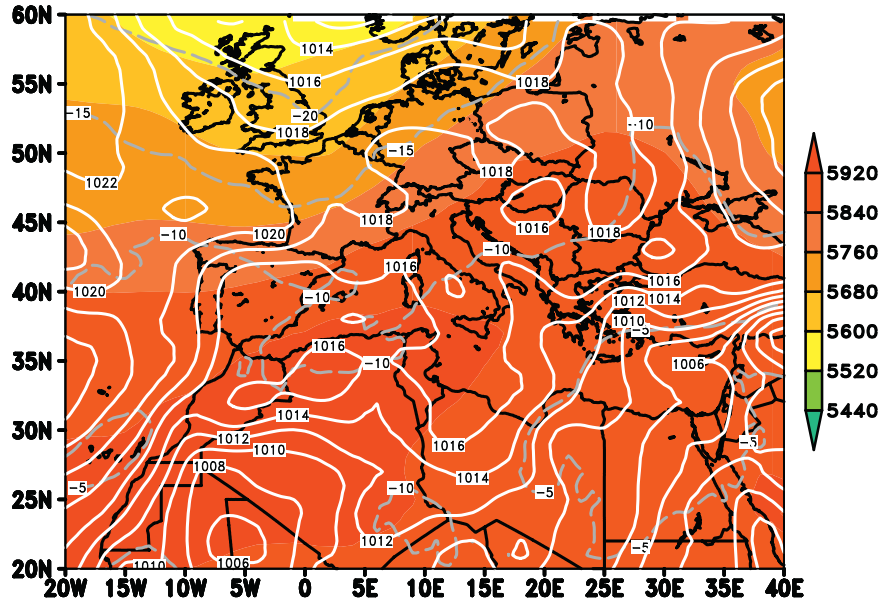

(d)

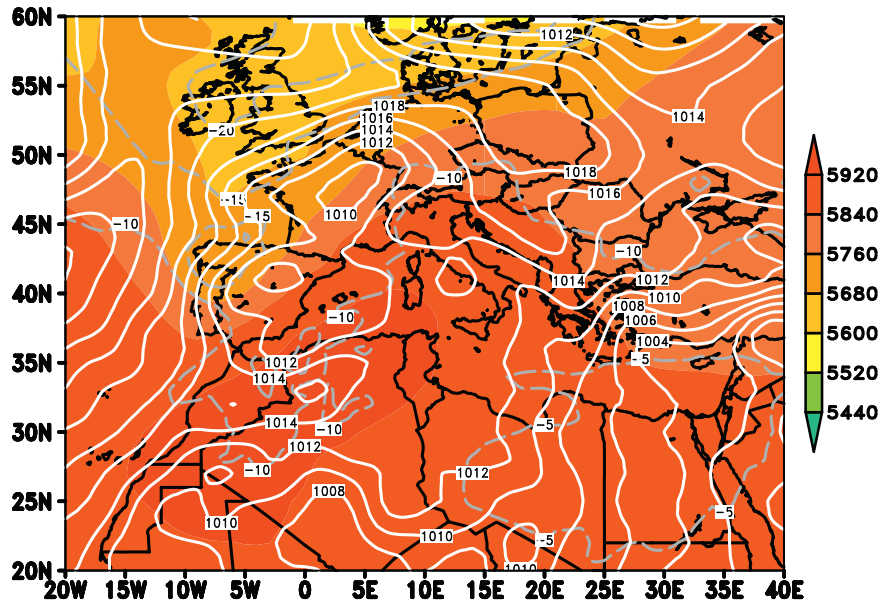

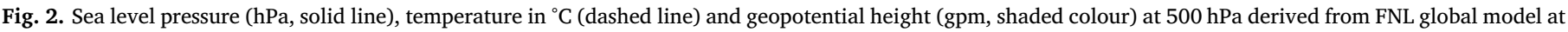
12 UTC on 7 (a), 10 (b), 11 (c) and 12 (d) July 2011.

WRF, an adjusted initial soil moisture field is used in the simulations performed in the current study, by applying a factor correction of 0.5 to the initial soil moisture, following the method adopted by Kalverla et al. (2016).

Given the critical need to produce skilful model-simulated meteorological and surface parameters forecasts for applications that could take advantage of these products, as mentioned above, and especially to those operations that rely on MMMs, such as air quality forecasting systems (see e.g. Borge et al., 2008; Banks et al., 2016), wind resources assessment and prediction (see e.g. Santos-Alamillos et al., 2015; Draxl et al., 2014; Avolio et al., 2016; Giannaros et al., 2017), or irradiance forecasting for solar radiation applications (see e.g. Lara-Fanego et al., 2016; Gómez et al., 2016a; Avolio et al., 2016; Federico et al., 2017), there is a strong need to further evaluate the results produced by these models against observations, in order to understand the origin of model limitations and strengths. Therefore, the main aim of the current study is to perform a comprehensive evaluation of these two state-of-the-art MMMs, RAMS and WRF, so as to try to determine what are the strengths of both models regarding meteorology and surface parameters as well as to analyse how these models perform and contrast in the simulation of key physical processes. In this regard, we have considered one case study covering four distinct atmospheric conditions typical of the study area. To compare these two MMMs, first we make use of various available surface observations. On the other hand, we include remote sensing products, such as different surface data derived from the
Meteosat Second Generation (MSG) Spinning Enhanced Visible and Infrared Imager (SEVIRI) (MSG-SEVIRI; Prata, 1996; Caselles et al., 1997; Brisson et al., 1999; Trigo et al., 2008). Finally, we include the uncoupled Land Surface Model (LSM) Global Land Data Assimilation System (GLDAS; Rodell et al., 2004) surface products as well. Combining satellite-derived data with that derived by uncoupled LSM models, together with surface observations, will provide a deeper insight on the performance of RAMS and WRF models, and will permit to assay how these MMMs compare with other atmospheric and surface datasets, widely used by researchers.

In the next sections, we first describe the methodology, models setup and datasets used (Section 2), followed by the simulation results and their discussion (Section 3) and the conclusions (Section 4).

\section{Datasets and methodology}

\subsection{Model configurations}

The selected forecasting period has been simulated based on two state-of-the-art NWP models, widely used by researchers and operational forecasters. The first one is the RAMS model (Cotton et al., 2003; Pielke Sr., 2013), version 6.0. The second one is the Advanced Research core of the WRF model (WRF-ARW; Skamarock et al., 2008), version 3.6.1. Both models use three nested domains with horizontal resolution of $48 \mathrm{~km}, 12 \mathrm{~km}$ and $3 \mathrm{~km}$, respectively, while a total of 45 levels were 
(a)

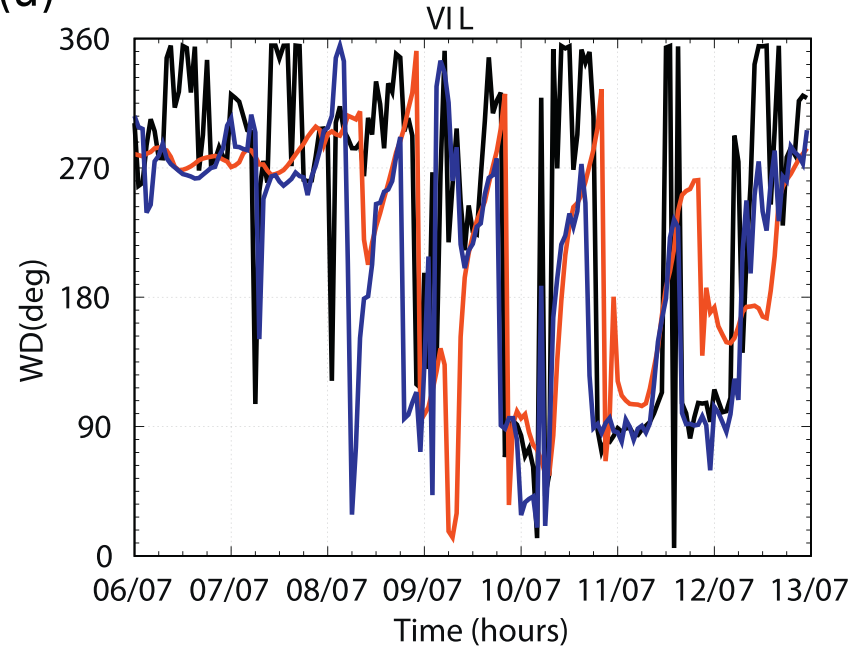

(c)

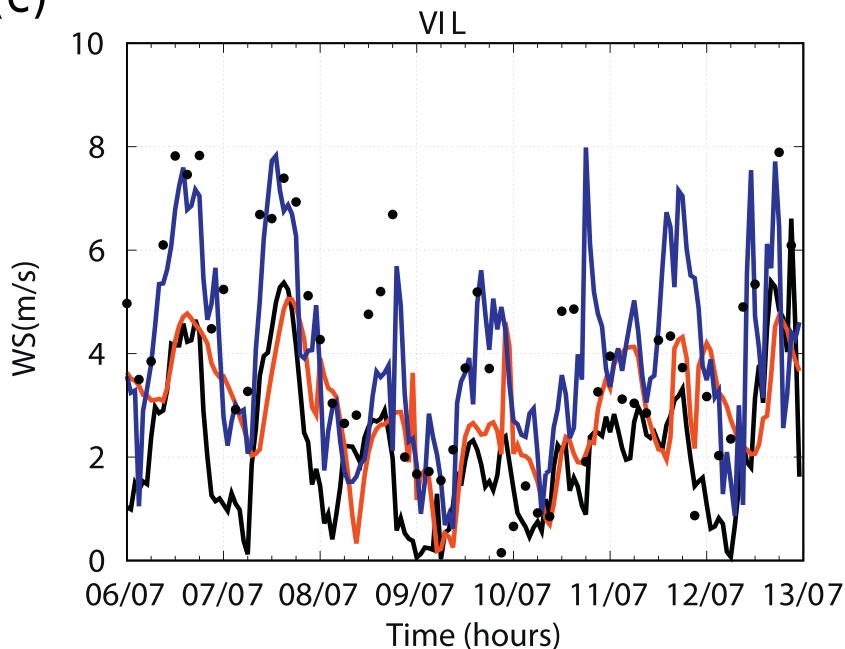

(b)

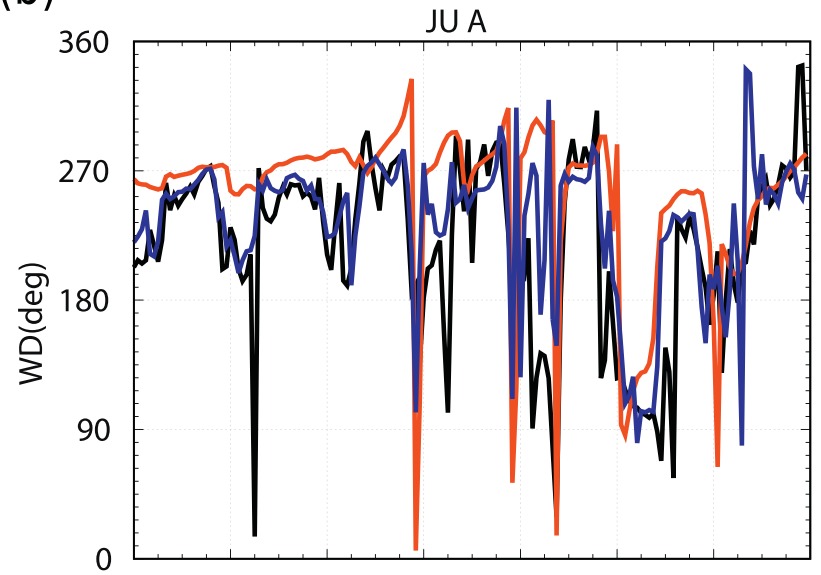

06/07 07/07 08/07 09/07 10/07 11/07 12/07 13/07

Time (hours)

(d)

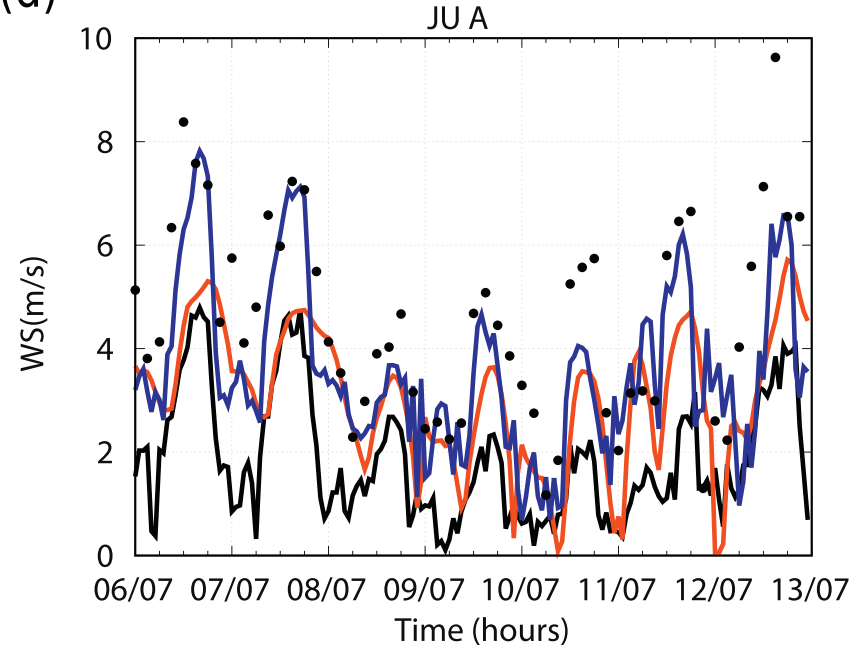

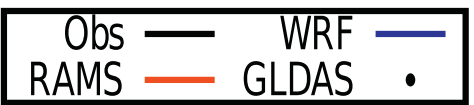



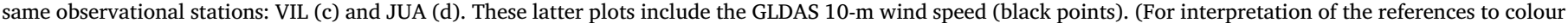
in this figure legend, the reader is referred to the web version of this article.)

selected in the vertical. Considering the WRF configuration, 24 levels are present in the lowest $2000 \mathrm{~m}$ while 9 levels are present in the lowest $300 \mathrm{~m}$. In the RAMS configuration, 22 levels are included in the lowest $2000 \mathrm{~m}$ while 8 levels are present in the lowest $300 \mathrm{~m}$. Due to the different modelling structure of RAMS and WRF, it is difficult to exactly match the grid configuration of both models. Nonetheless, we have tried to maintain a similar vertical grid configuration for RAMS and WRF in the current study.

Regarding physical parameterizations, both RAMS and WRF use the YSU PBL scheme (Hong et al., 2006; Gómez et al., 2016b). However, this PBL parameterization is coupled to the Land-Ecosystem Atmosphere Feedback Model (LEAF), in its version 3 (LEAF-3), in the RAMS simulations (Walko et al., 2000), while YSU is combined with the more recent and advanced Noah LSM (Chen and Dudhia, 2001a, 2001b; Ek et al., 2003), known as Noah-MP (Niu et al., 2011; Yang et al., 2011) in the WRF environment. In addition, the physical parameterization schemes used within WRF include the Dudhia shortwave radiation (Dudhia, 1989) and the rapid radiative transfer model (RRTM) longwave radiation (Mlawer et al., 1997) as radiation options, while the
Chen-Cotton scheme is used for longwave and shortwave radiation (Chen and Cotton, 1983) within the RAMS framework. On the other hand, the Kain-Fritsch scheme for convection is used by both RAMS (Castro et al., 2002) and WRF (Kain, 2004) on the two most outer grids. Finally, the cloud and precipitation microphysics scheme from Walko et al. (1995) is used in RAMS, while the WRF Single-Moment (WSM) 6class microphysics parameterization scheme (Hong and Lim, 2006) is applied in WRF.

RAMS and WRF are used to simulate the period from 6 to 12 July 2011. Four distinct atmospheric conditions dominate over the study area during this period. Due to the climatic and geographical conditions, in particular the orography and distances to the sea, the area of study is influenced by land-sea contrasts (Gómez et al., 2016c). In this regard, typical atmospheric conditions over the area during the summer are related to mesoscale circulations associated with sea-land breezes. However, Western synoptic advections, related to high temperatures and intense-heat situations, as well as Mediterranean or Eastern synoptic advections (Gómez et al., 2014c) are also common over this area during this period of the year. Fig. 2 shows the general synoptic 
(a)

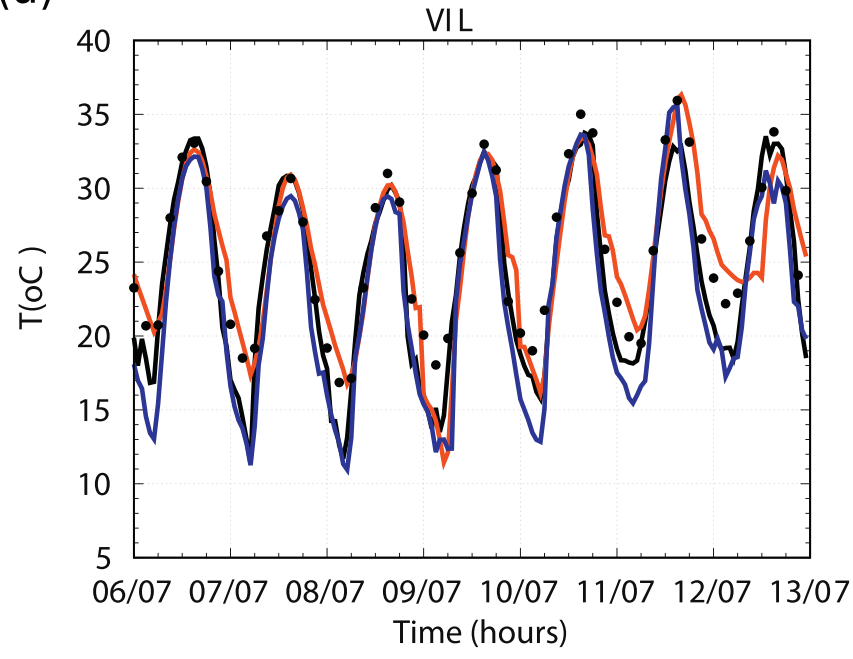

(c)

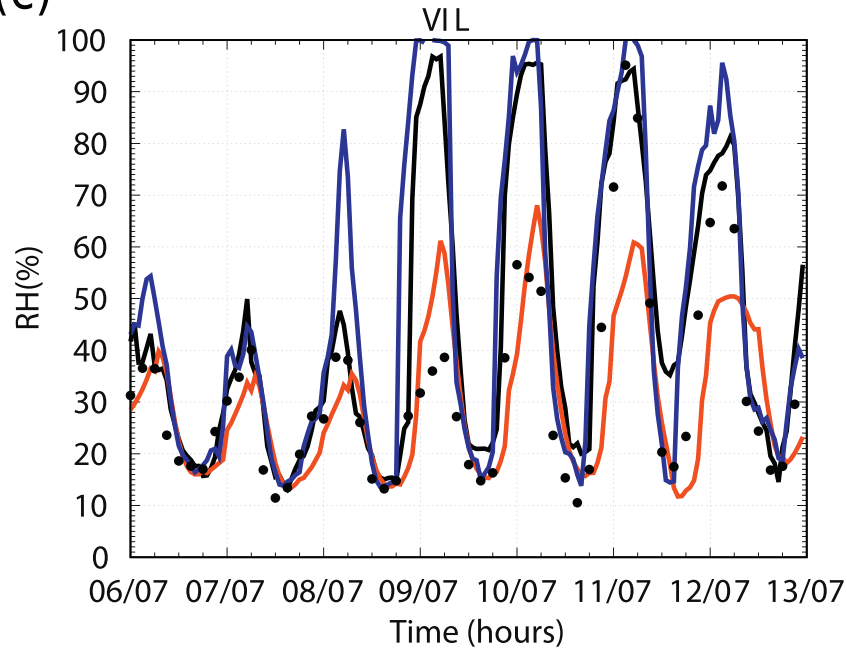

(b)

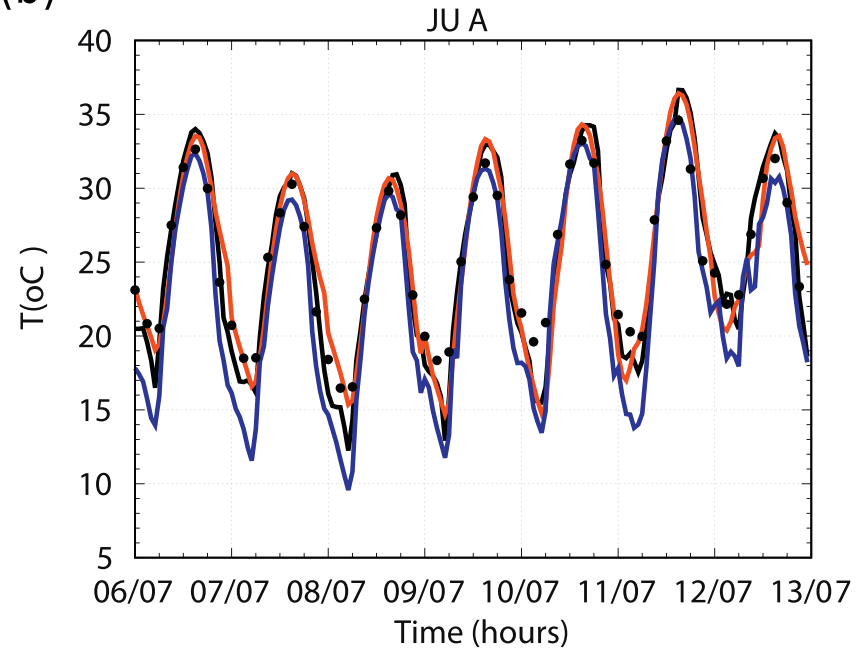

(d)

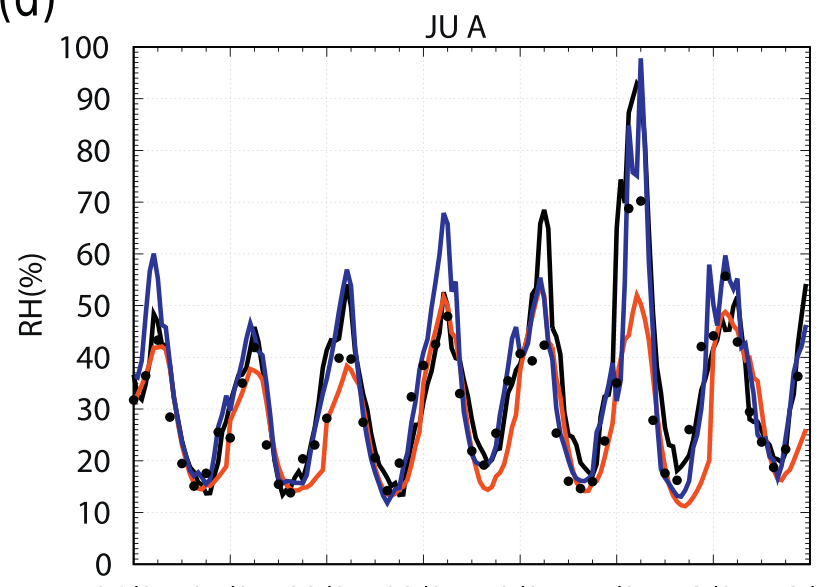

06/07 07/07 08/07 09/07 10/07 11/07 12/07 13/07

Time (hours)

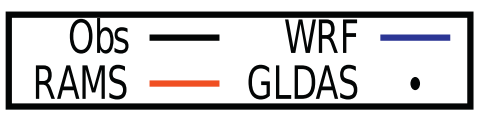

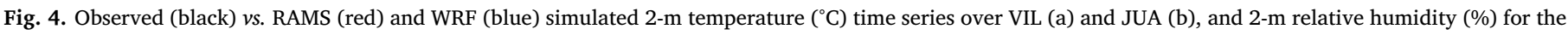

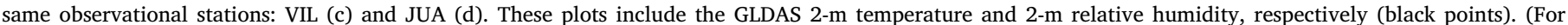
interpretation of the references to colour in this figure legend, the reader is referred to the web version of this article.)

situation on 7, 10, 11 and 12 July 2011. The main meteorological feature on 6 to 8 July is the presence of a Western synoptic advection (Gómez et al., 2018), producing high wind speeds and low atmospheric moisture over the study area. Mesoscale circulations are developed on 9 and 10 July, showing a clear transition between the day and night winds. On the other hand, an Eastern synoptic advection is well established on 11 July, while 12 July is characterised by the presence of another Western synoptic advection, but with the presence of some scattered cloudiness in this case. For each of these days, both models have been used in re-forecast mode, performing a daily simulation with a forecast horizon of $36 \mathrm{~h}$ and a temporal resolution of $1 \mathrm{~h}$, starting at 12 UTC the previous day. Therefore, the first $12 \mathrm{~h}$ are left out as a spinup period and only the remaining $24 \mathrm{~h}$ are considered in the evaluation. The NCEP FNL dataset at $1 \times 1$ degree resolution globally and $6 \mathrm{~h}$ temporal resolution were used as initial and boundary conditions for both RAMS and WRF. Taking into account that the soil moisture provided by FNL has been shown to produce high values for this initial field, the simulations performed using RAMS and WRF have been configured by applying a factor correction to the initial soil moisture. In this sense, the magnitude has been reduced to the half, that is multiplying this parameter by a factor of 0.5 (Kalverla et al., 2016).

\subsection{Observational and modelling datasets}

Firstly, hourly measures of 2-m temperature and relative humidity, $10-\mathrm{m}$ wind speed and direction and incident shortwave radiation observations of two weather stations belonging to the SIAR (Sistema de Información Agroclimática para el Regadío; Agroclimatic Information System for Irrigation; http://eportal.mapama.gob.es/websiar/Inicio. aspx) system, operated by the Spanish Ministry of Agriculture, Food and Environment, are used in the current study (Villanueva de la Jara, VIL; and Juanaco, JUA; Fig. 1). The selection of these two weather stations to presents the results obtained in the current study is based on the differences found in the models' results under distinct wind regimes, as it will be seen in the results section.

Secondly, the uncoupled Land Surface Model (LSM) Global Land Data Assimilation System (GLDAS; Rodell et al., 2004) is also used in this regard. The dataset used in the current study is the Noah LSM 

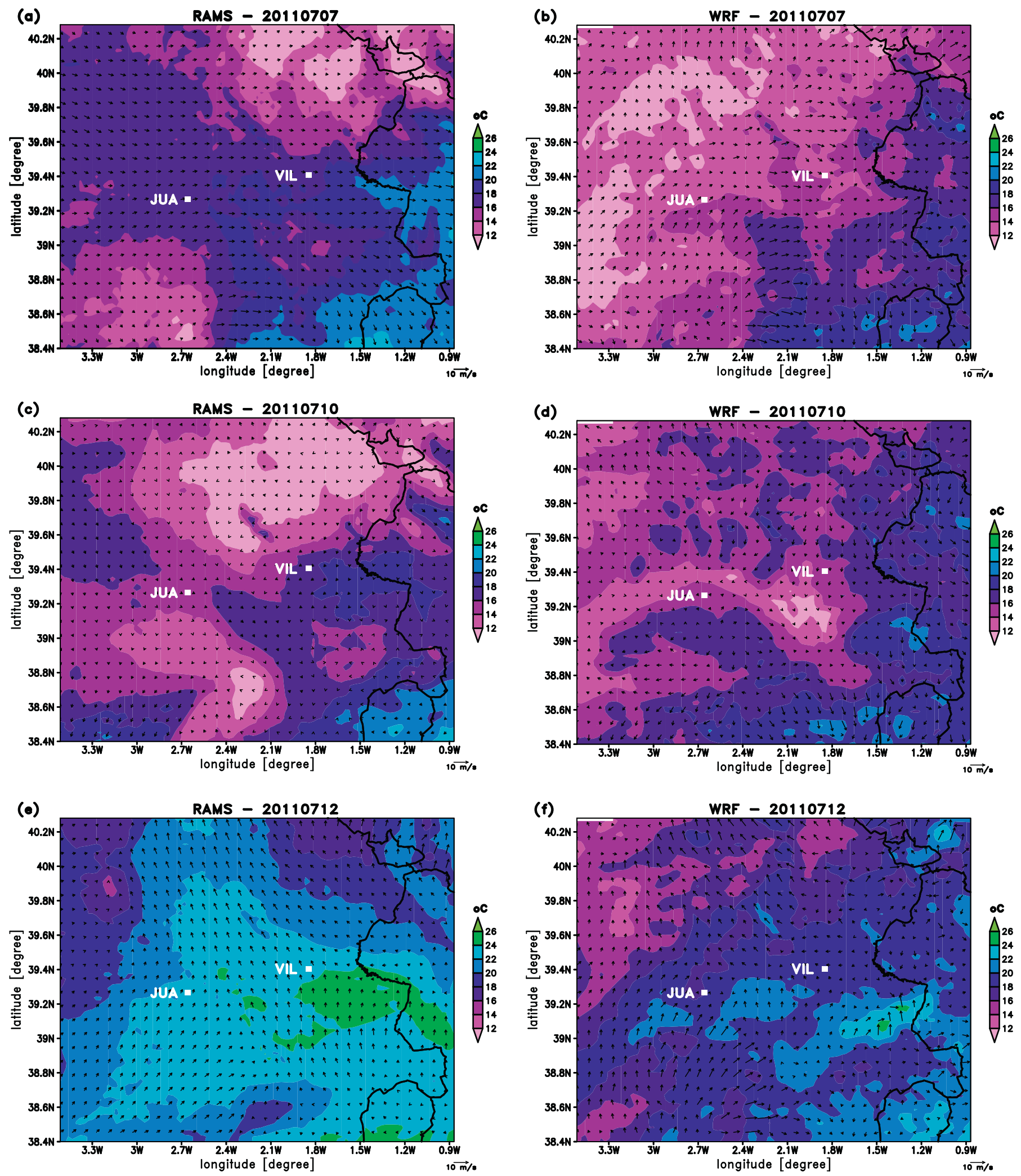

Fig. 5. Comparison of RAMS and WRF 10-m wind field (scale: $10 \mathrm{~m} / \mathrm{s}$ ) and 2-m temperature $\left({ }^{\circ} \mathrm{C}\right.$ ) over the inner simulation domain on 7 July 2011 at 06 UTC (RAMS, a; WRF, b; Western synoptic advection), 10 July 2011 at 06 UTC (RAMS, c; WRF, d; mesoscale circulation), 12 July 2011 at 06 UTC (RAMS, e; WRF, f; Western synoptic advection with the presence of cloudiness).

produced by GLDAS version 1 with a 3-hourly temporal resolution, which is based on 4 soil layers $(0-0.1,0.1-0.4,0.4-1.0,1.0-2.0 \mathrm{~m})$ and is generated with a horizontal spatial resolution of $0.25 \times 0.25$ degree globally. The air temperature, relative humidity and wind speed, the incident shortwave and longwave radiation, the surface sensible sensible and latent heat fluxes, as well as the skin temperature and the soil moisture fields are used for the models' assessment.

Finally, satellite data obtained from the Meteosat Second 

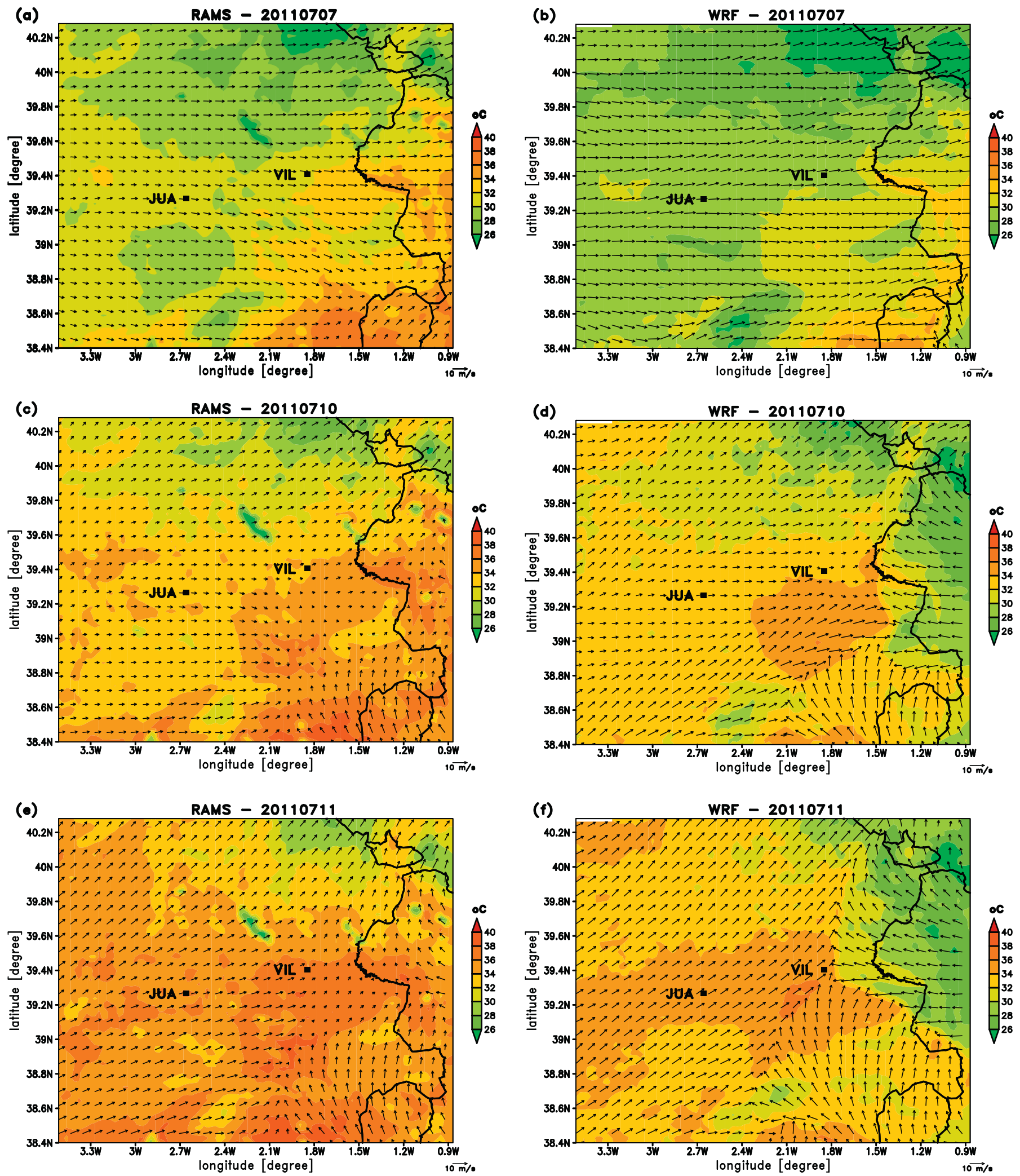

Fig. 6. Comparison of RAMS and WRF 10-m wind field (scale: $10 \mathrm{~m} / \mathrm{s}$ ) and 2-m temperature $\left({ }^{\circ} \mathrm{C}\right.$ ) over the inner simulation domain on 7 July 2011 at 15 UTC (RAMS, a; WRF, b; Western synoptic advection), 10 July 2011 at 15 UTC (RAMS, c; WRF, d; mesoscale circulation), 11 July 2011 at 15 UTC (RAMS, e; WRF, f; Eastern synoptic advection).

Generation (MSG) Spinning Enhanced Visible and Infrared Imager (SEVIRI) (MSG-SEVIRI) is also used in the current study. The Land Surface Temperature (LST; Caselles et al., 1997; Trigo et al., 2008), the Downward Surface Shortwave Flux (DSSF; Brisson et al., 1999), and the
Downward Surface Longwave Flux (DSLF; Prata, 1996) MSG-derived high-level products generated by the Land Surface Analysis Satellite Applications Facility (LSA SAF), located at the Portuguese Meteorological Institute in Lisbon, are used for the models' assessment. These 
(a)

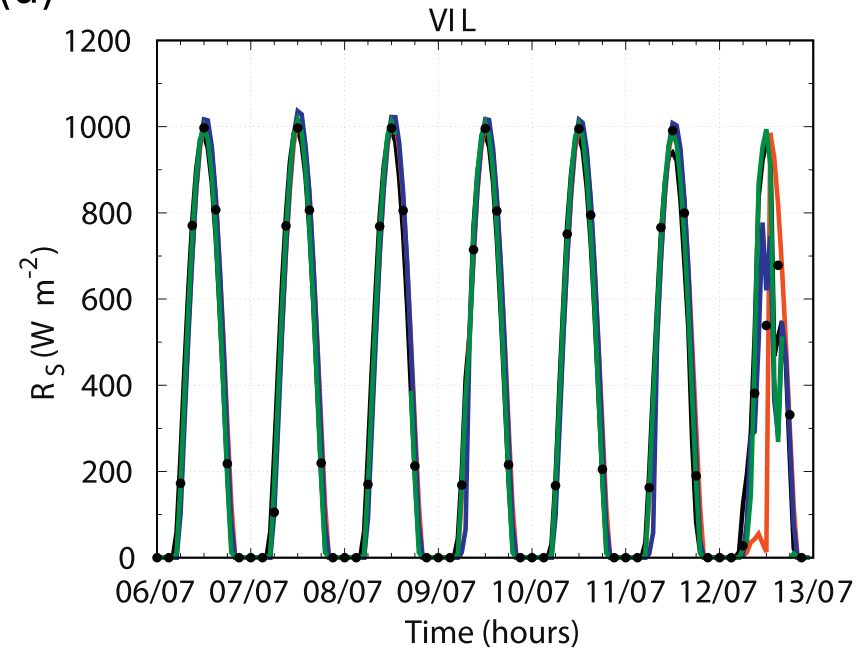

(c)

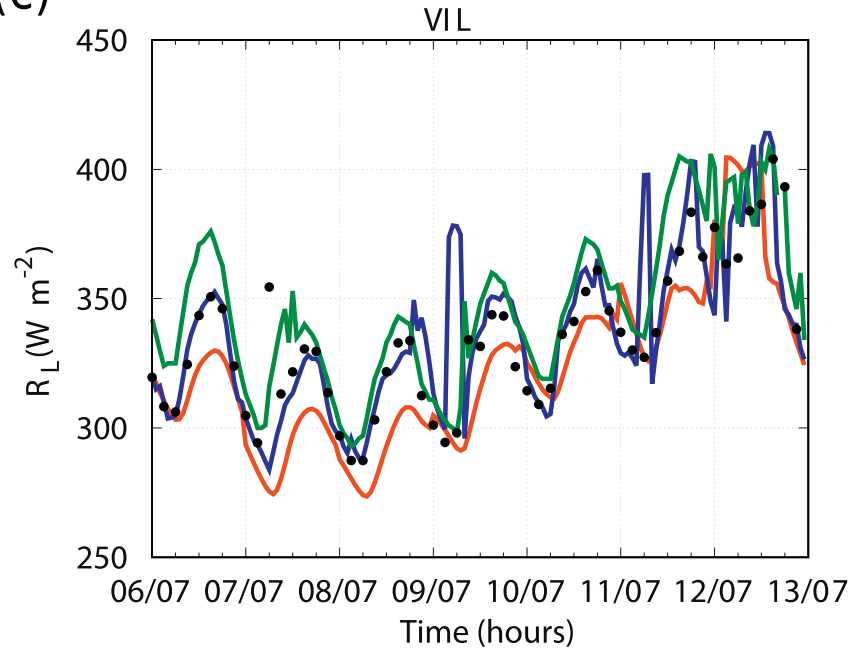

(b)

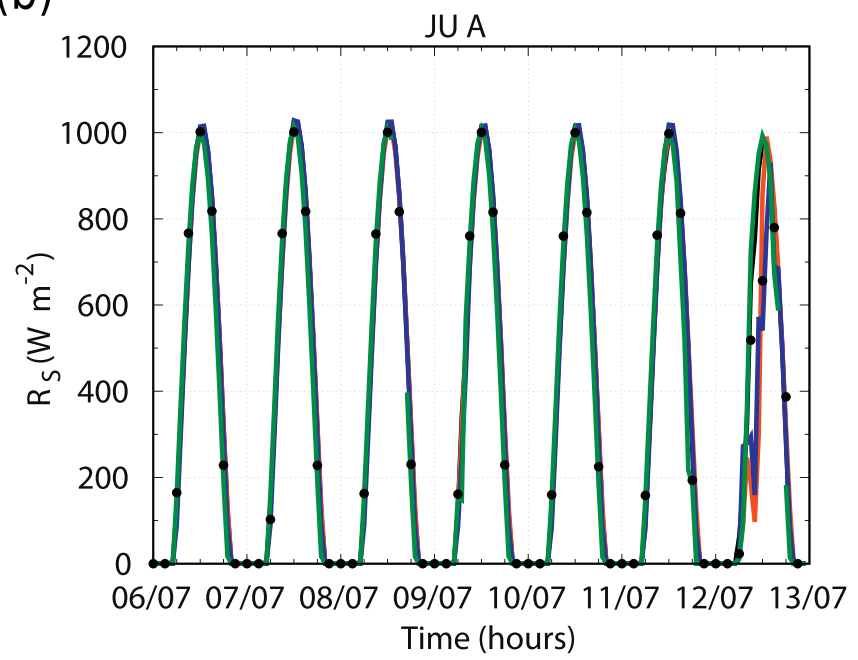

(d)

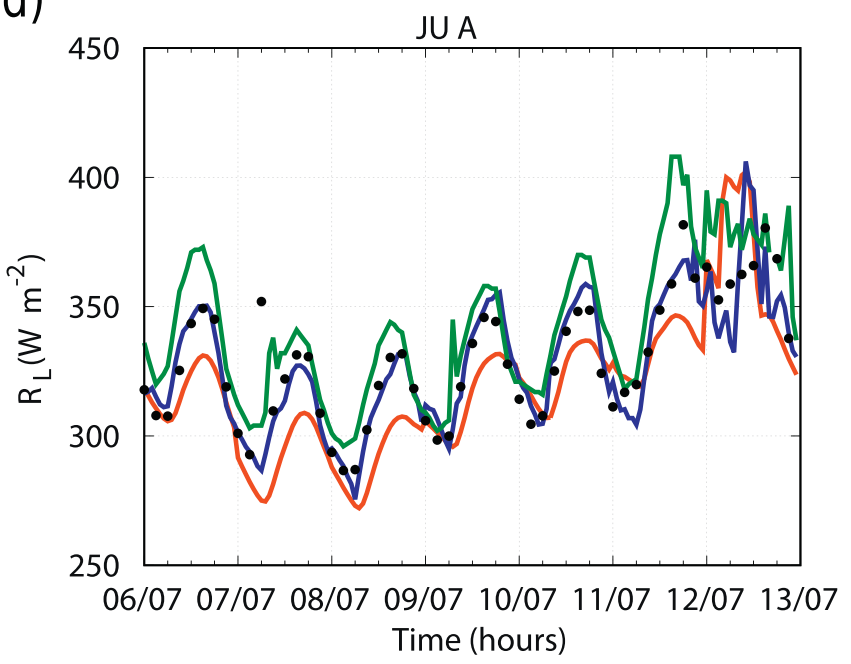

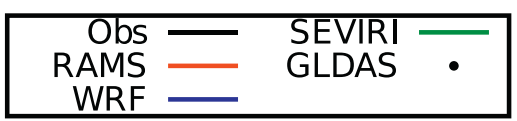

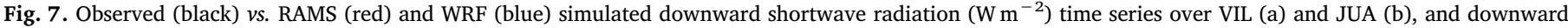

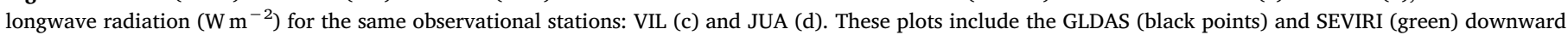

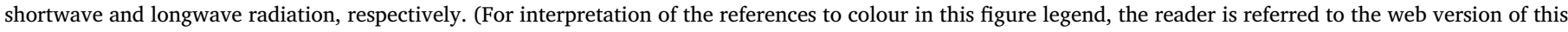
article.)

products are generated with the spatial resolution and projection of the MSG-SEVIRI instrument data, considering a nominal resolution of $1 \mathrm{~km}$ (footprint of around $3 \times 4.5 \mathrm{~km}$ in the study area).

In order to conduct a comprehensive assessment of RAMS and WRF, all this information is used. On the one hand, in-situ observations measured by the SIAR system and remote sensing observations derived from the SEVIRI instrument onboard MSG. On the other hand, modelling data provided by the uncoupled LSM GLDAS. The combination of in-situ with remote sensing observations maybe used to generate additional information when a single source dataset does not provide all the information required. In this regard, both datasets are used in a complementary sense. Furthermore, remote sensing observations could be used to validate maps in comparison to sampled in-situ observations.

\section{Results and discussion}

\subsection{How do RAMS and WRF simulations compare over the study area?}

We start the analysis of results with the wind field in order to introduce the dominant atmospheric conditions over the study area within the simulation period, that will be useful when tackling other meteorological variables. Fig. 3 shows the observed wind field for the two weather stations, VIL and JUA, where the corresponding dominant meteorological features are highlighted.

In general, both RAMS and WRF properly reproduce the main wind patterns of the observed atmospheric conditions, with little differences between the two mesoscale models in the wind direction forecasts (Fig. 3). In terms of the wind speed, WRF and RAMS are in general more windy than the observations, especially at night-time, as indicated by the positive MBE values in Table 1, both over VIL and JUA. However, RAMS is able to properly capture the observed wind speed at daytime under the Western synoptic conditions, with an MBE of 0.6 
(a)

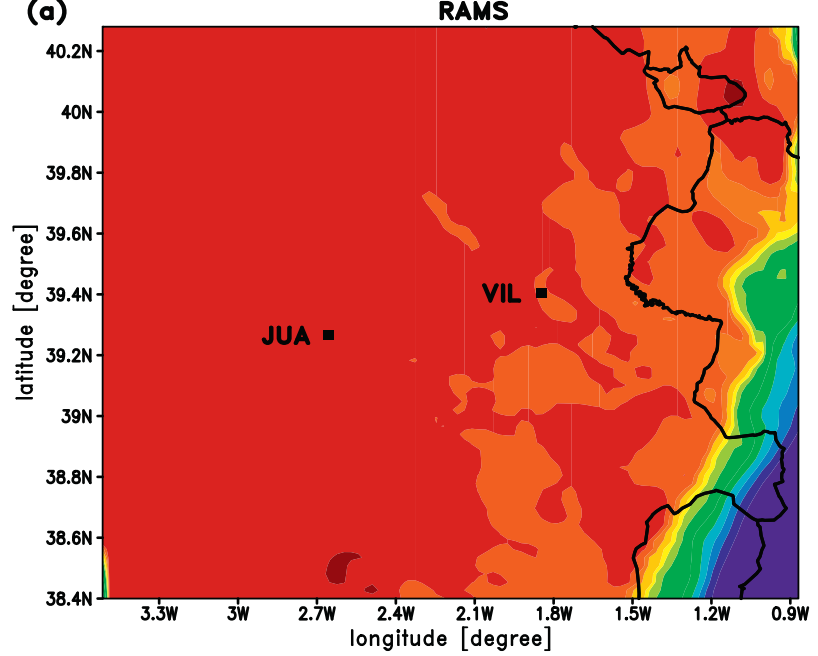

(c)

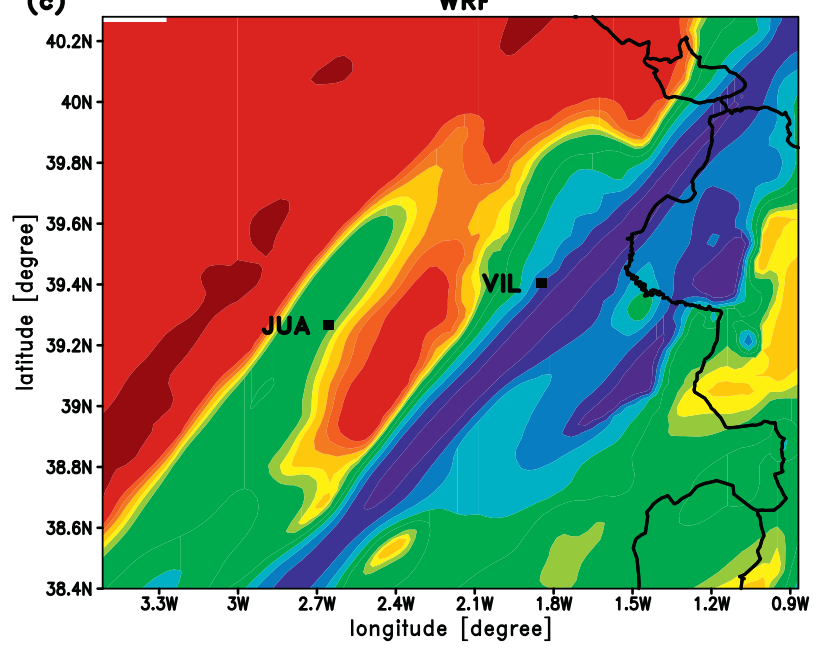

\section{(e)}

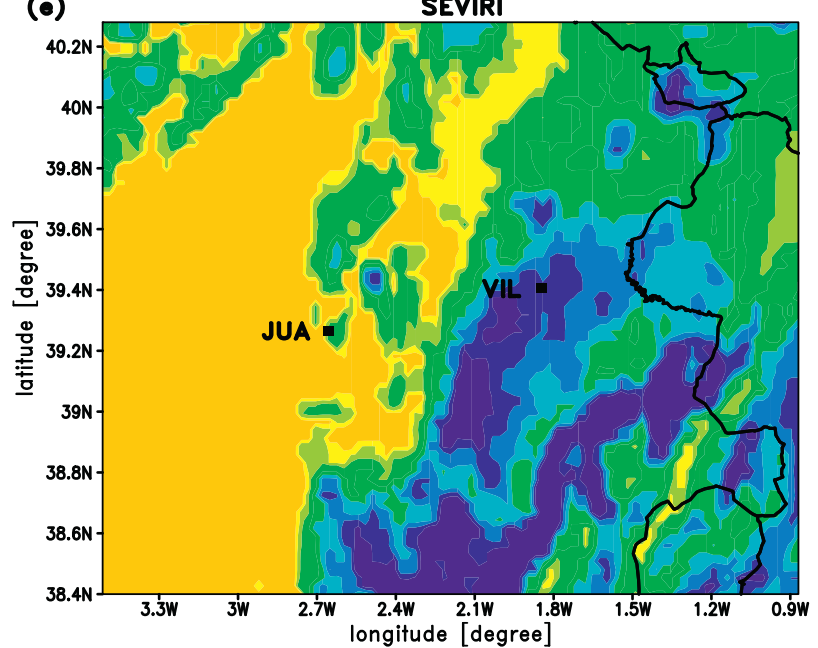

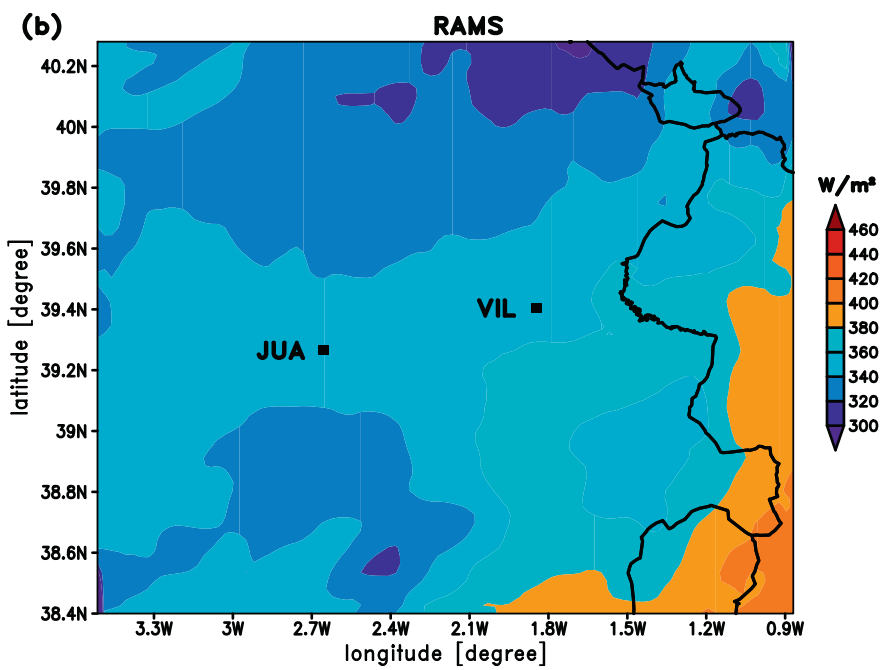
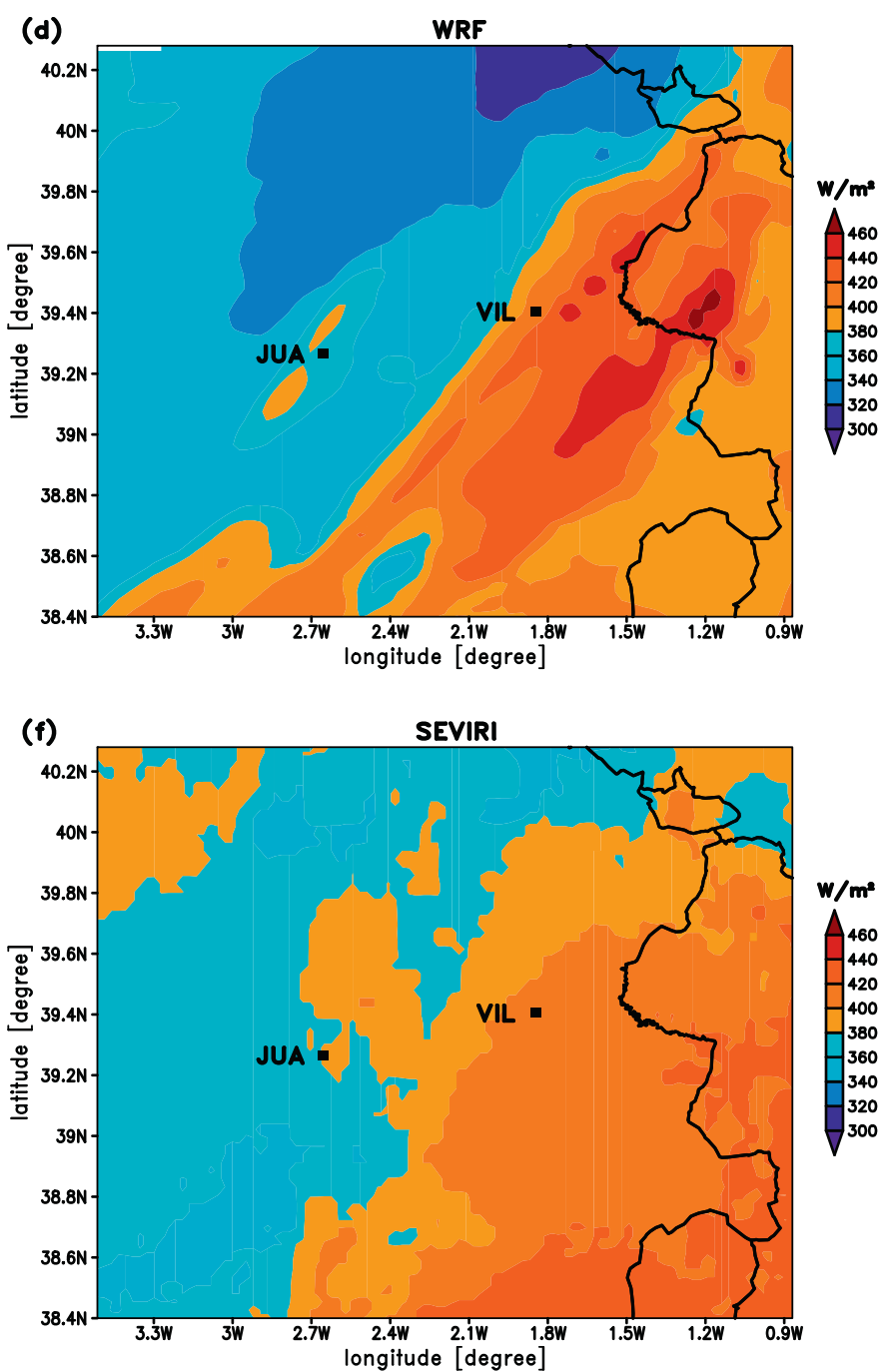

Fig. 8. RAMS and WRF forecasts $v$. MSG-SEVIRI derived downward shortwave radiation (RAMS, a; WRF, c; SEVIRI-DSSF, e) and downward longwave radiation (RAMS, b; WRF, d; SEVIRI-DSLF, f) on 12 July 2011 at 15 UTC.

and $-0.18 \mathrm{~m} / \mathrm{s}$ over JUA and VIL, respectively, and an RMSE of $0.7 \mathrm{~m} /$ $\mathrm{s}$ in both cases.

The general overestimation of the WRF modelled wind speed found in the current study is in agreement with other studies performed using this mesoscalar model over different regions (see e. g. Borge et al.,
2008; Draxl et al., 2014; Hariprasad et al., 2014; Santos-Alamillos et al., 2015; Banks and Baldasano, 2016; Kalverla et al., 2016; Avolio et al., 2017). A plausible reason for this wind speed overestimation could be a lack of frictional drag near the surface (Kalverla et al., 2016). Additionally, the comparison of RAMS and WRF wind speed has been 

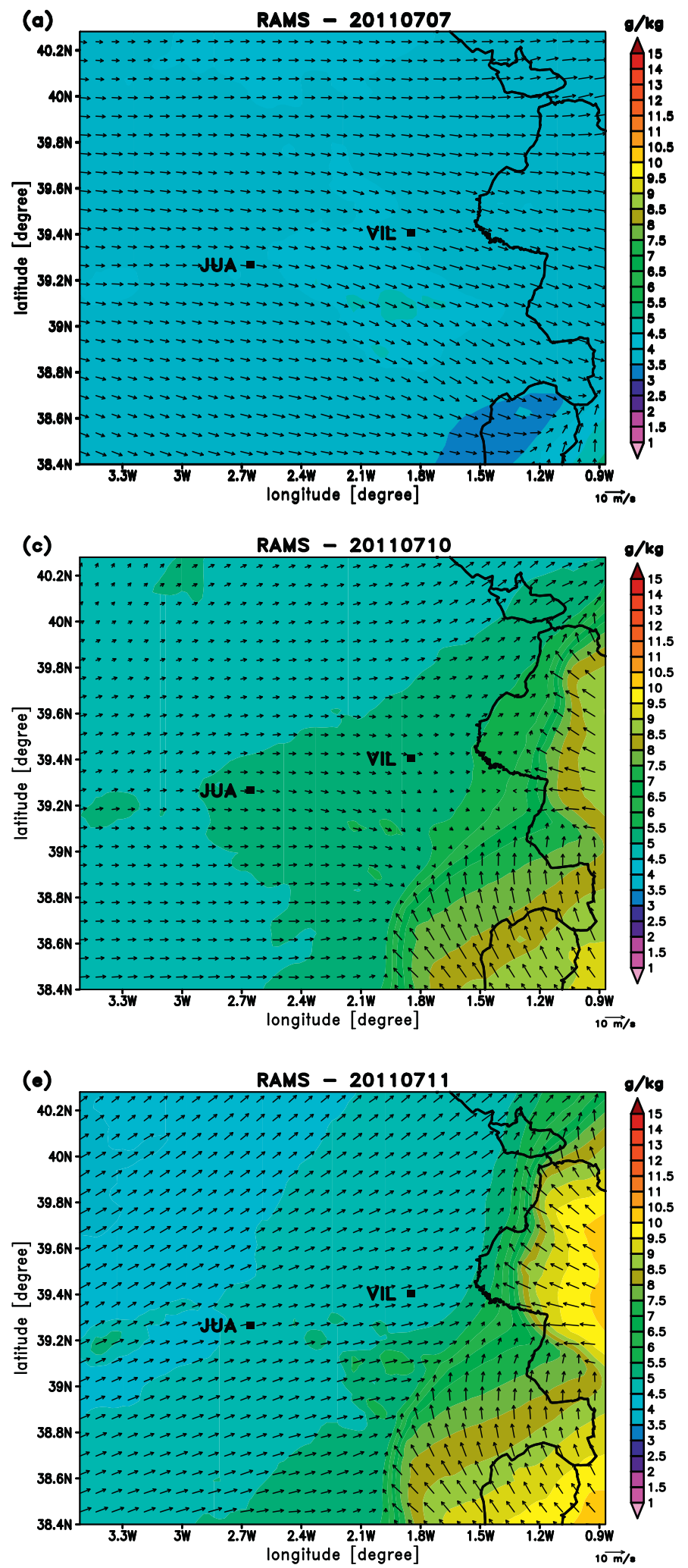
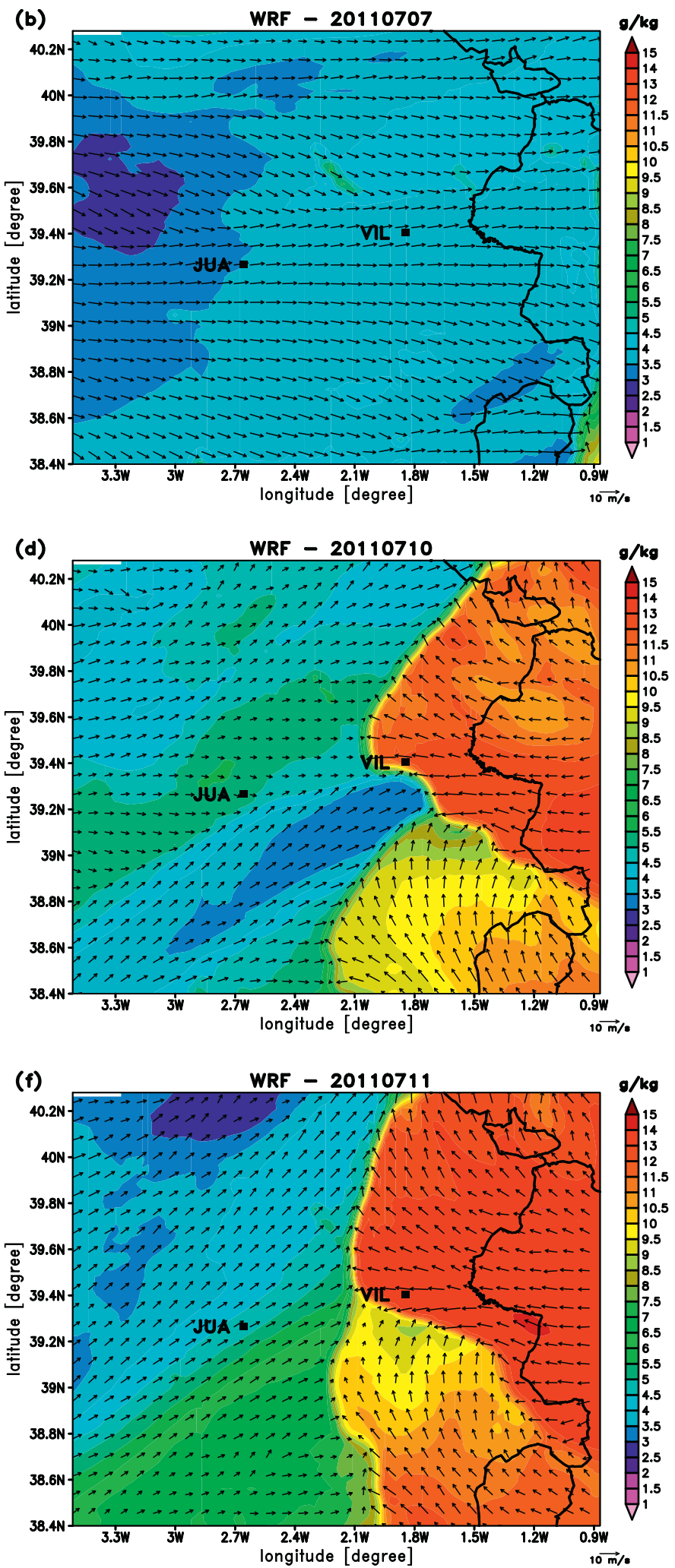

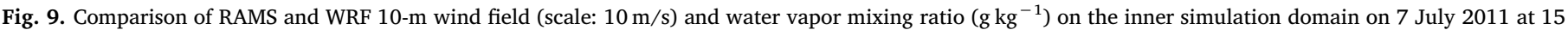

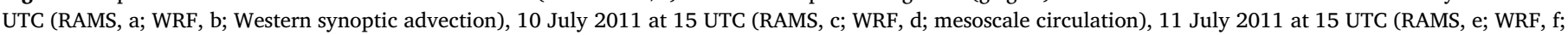
Eastern synoptic advection).

investigated previously by Steeneveld et al. (2011) over Cabauw tower in the Netherlands and by Avolio et al. (2016) over southern Italy. They found that both RAMS and WRF present a good performance in terms of the wind forecast, even though RAMS showed a slightly better performance than WRF in general.

Considering the 2-m temperature (Fig. 4), RAMS reproduces well the daytime temperature in all weather station locations (Table 2), with a mean maximum temperature difference of $-0.11^{\circ} \mathrm{C}$ over JUA and of 

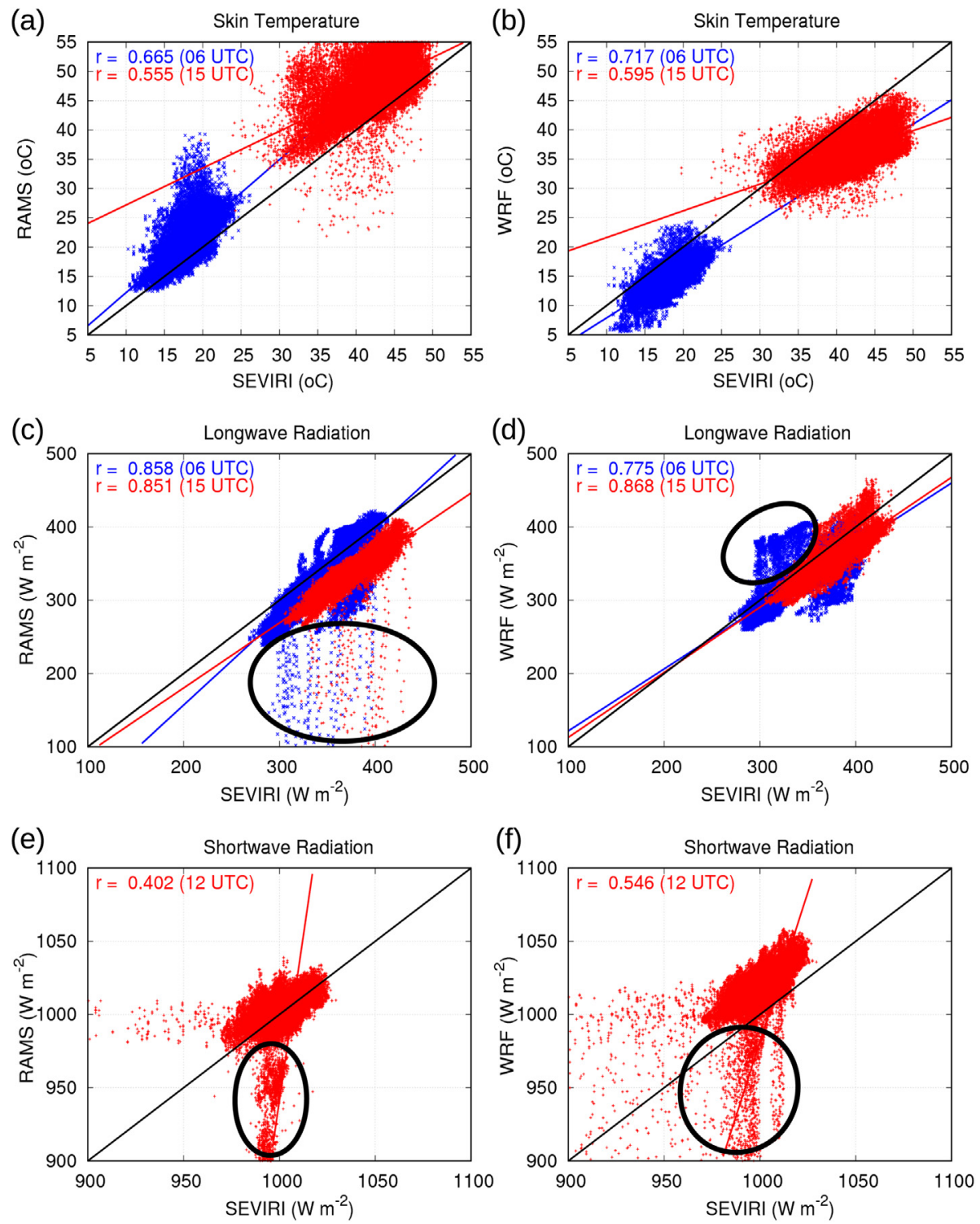

Fig. 10. RAMS and WRF forecasts vs. MSG-SEVIRI derived data at night-time (06 UTC; blue) and during the day (15 UTC; red), considering the period 6 to 12 July 2011: RAMS skin temperature $\left({ }^{\circ} \mathrm{C}\right.$; a), WRF skin temperature $\left({ }^{\circ} \mathrm{C}\right.$; b), RAMS downward longwave radiation $\left(\mathrm{W} \mathrm{m}^{-2}\right.$; $\left.\mathrm{c}\right)$, WRF downward longwave radiation $\left(\mathrm{W} \mathrm{m}{ }^{-2}\right.$; d). RAMS downward shortwave radiation $\left(\mathrm{W} \mathrm{m}^{-2}\right.$; e) and WRF downward shortwave radiation $\left(\mathrm{W} \mathrm{m}^{-2} ; \mathrm{f}\right)$ are presented at 12 UTC. (For interpretation of the references to colour in this figure legend, the reader is referred to the web version of this article.)

$0.2^{\circ} \mathrm{C}$ over VIL (Table 3$)$. RAMS properly captures the minimum temperatures over JUA, as indicated by a difference of -0.8 and $0.4{ }^{\circ} \mathrm{C}$ over JUA and VIL, respectively, on 10 July (Table 3 and Fig. 4). On the other hand, the 2-m temperature simulated by WRF presents a general underestimation of the maximum temperatures (Table 3). In this case, there is also a general trend to underestimate the minimum temperatures, with negative MBE (Table 2). Some reasons to explain the WRF daytime cold bias have been pointed out in previous studies (see e.g. Hu et al., 2010; Steeneveld et al., 2011). A more recent study performed by Avolio et al. (2017) over the Mediterranean area in Calabria Region (Southern Italy) points that this model issue could be related to an overestimation of the surface wind that transport moist and cold air from the sea under breeze circulations. They consider that an overestimation of this flow from the sea could produce this temperature cold bias. In the current study, reducing the initial soil moisture content to the half leads to a better adjustment between WRF and the observations, according to the results found by Kalverla et al. (2016).

Fig. 5 and Fig. 6 compare the wind field and 2-m temperature obtained by RAMS and WRF for the whole simulation region. In order to highlight the distinct atmospheric conditions considered in the current study, the differences between day and night-time in the wind flow are introduced. In this sense, Fig. 5 shows these magnitudes at 06 UTC while Fig. 6 displays the same results but at 15 UTC.

In terms of the $2-\mathrm{m}$ relative humidity, values around $50 \%$ or even lower are found in general at night under the Western synoptic advection on 6 to 8 July 2011, while they reach values $>90 \%$ under mesoscale circulations on 9 and 10 July 2011 over VIL as well as on 11 July over JUA. Even though the daily and day to day relative humidity cycle is reproduced by RAMS, the results obtained points towards an underestimation of the observed relative humidities under Eastern flows, corresponding to both synoptic and mesoscale circulations (Table 2). In contrast, WRF better simulates the daily and day to day relative humidity cycle (Fig. 4) as well as the observed values of this magnitude at night-time for the whole simulation period, with an RMSE lower than $10 \%$ at night-time over VIL under the Eastern synoptic advection and mesoscale circulations.

Higher differences in the relative humidity are observed during the day over VIL on 11 July, due to the important transport of moisture 
(a)

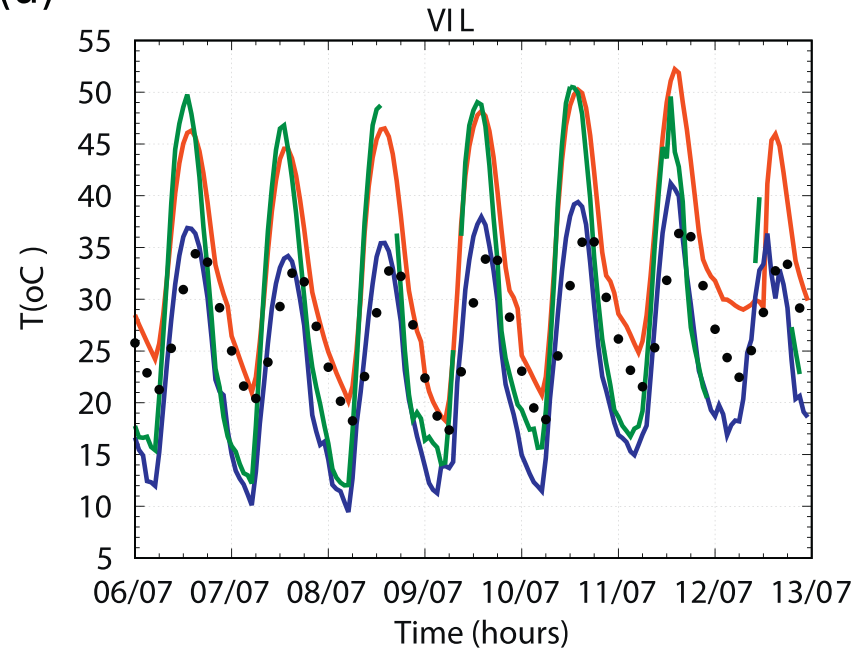

(c)

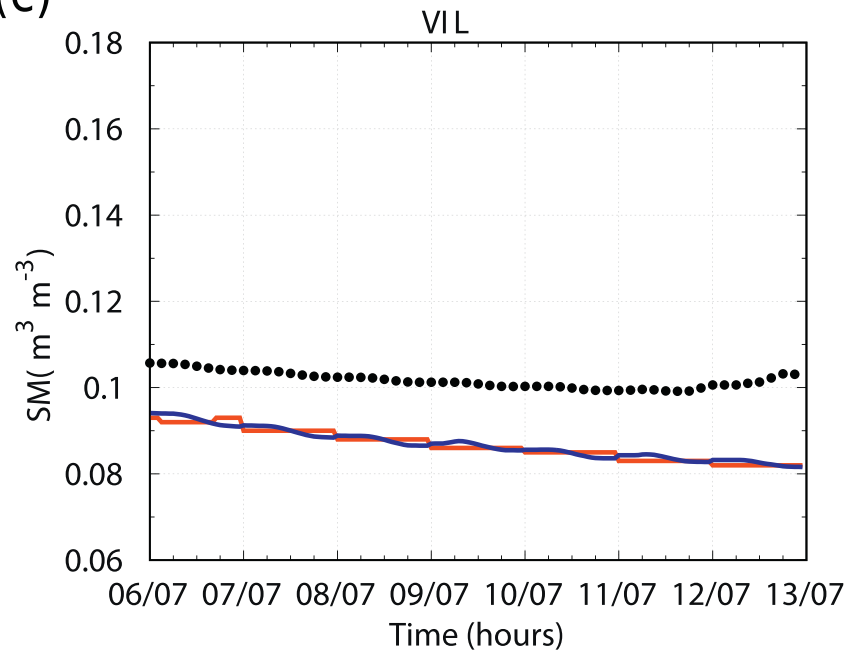

(b)

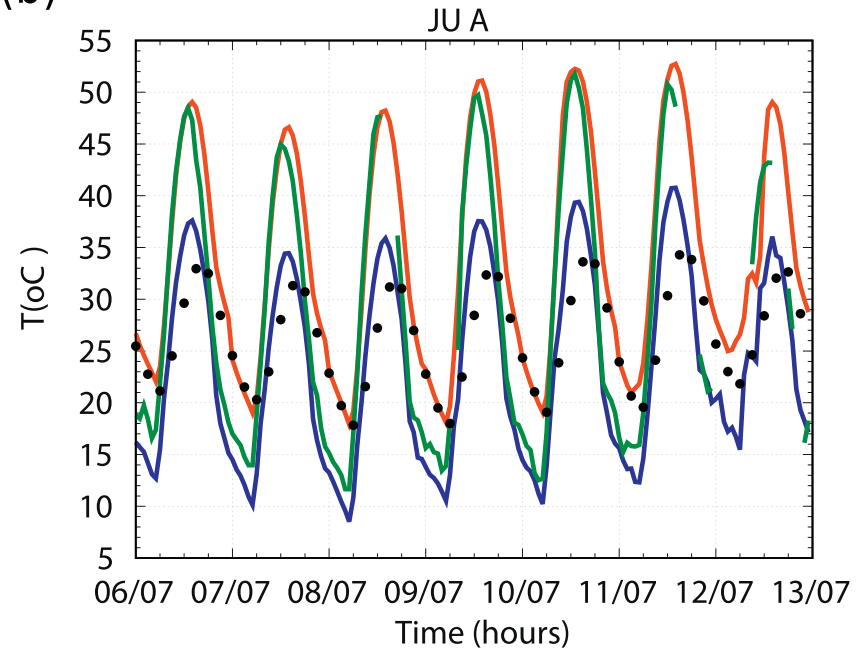

(d)

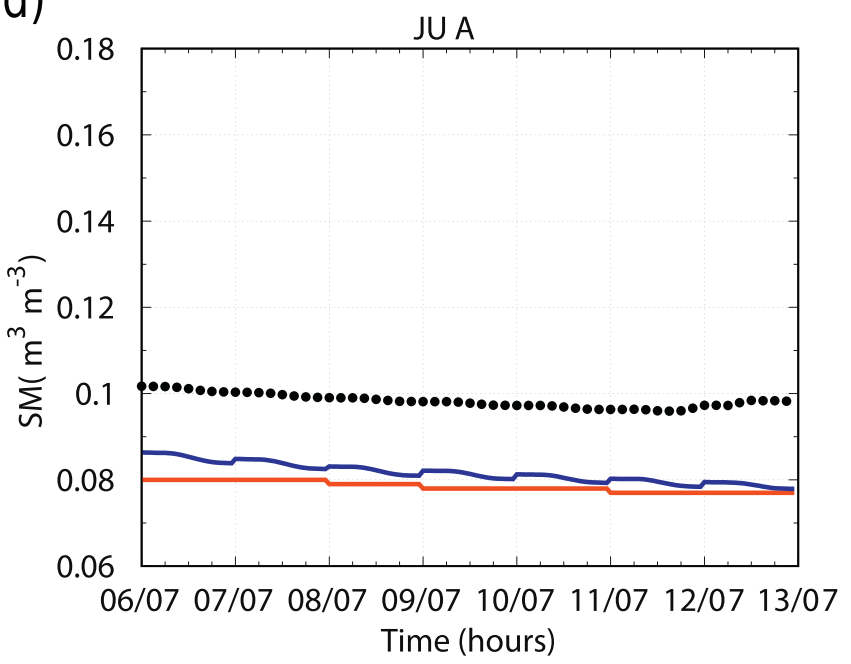

\begin{tabular}{|ll|} 
RAMS & SEVIRI \\
WRF & GLDAS \\
\hline
\end{tabular}

Fig. 11. Comparison of RAMS (red) and WRF (blue) simulated skin temperature $\left({ }^{\circ} \mathrm{C}\right.$ ) time series over VIL (a) and JUA (b), and soil moisture content of the uppermost soil layer $\left(\mathrm{m}^{3} \mathrm{~m}^{-3}\right.$ ) for the same observational stations: VIL (c) and JUA (d). The skin temperature plot includes this magnitude as well for SEVIRI (green) and GLDAS (black points). The soil moisture content plot includes this magnitude for the GLDAS product (black points). (For interpretation of the references to colour in this figure legend, the reader is referred to the web version of this article.)

inland by the Eastern synoptic forcing. In this case, neither RAMS nor WRF are able to capture this high daytime moisture. As a result, an overestimation of the daytime temperature is simulated by both models (Fig. 4c,a and Fig. 6e,f). However, in this case, the skilful results of the wind direction simulated by WRF sooner corrects the relative humidity and the temperature fields, leading to a better representation of the minimum temperature on 12 July using this model (Fig. 5e,f). In contrast, as RAMS is delayed in the entrance of the Eastern flow, this model takes longer to transport moisture inland, thus producing the observed overestimation of the minimum temperature on 12 July.

Looking at the incident shortwave radiation field (Fig. 7), little differences are observed between RAMS and WRF (Table 4). In addition, both models tend to produce cloudiness over the region of study on 12 July, even though more divergences are shown in relation to the occurrence and pass of the clouds (Fig. 7a,b). The observations of the downward shortwave radiation show some persistent clouds over both JUA and VIL throughout 12 July, confirmed by satellite images (Fig. 8e,f). Even though both models simulate the persistence of clouds over these weather station locations, Fig. 7 and Fig. 8 show the difficulties found in mesoscale modelling to forecast this kind of clouds. For instance, RAMS shows abundant cloudiness over VIL until midday (not shown), but this model simulates a cloudless sky approximately from this time on (Fig. 8a,b). This is the reason of the higher differences observed in Table 4 over this weather station using this model on 12 July. Previous studies have shown notable differences between the irradiation produced by these mesoscale models and the corresponding observations, as in Gómez et al. (2016a) or Federico et al. (2017) in the case of RAMS, or in Lara-Fanego et al. (2012) in the case of WRF. Additionally, comparison of both models have shown slightly larger errors in WRF in comparison to those calculated for RAMS (Avolio et al., 2016). Focusing on cloudy conditions or considering the case where all atmospheric conditions are merged, the current study shows a downward shortwave radiation in line with that presented in these previous studies. However, taking into account specific atmospheric conditions (Table 4), lower errors are obtained in the current study considering the other three atmospheric conditions.

Therefore, it seems important to consider the corresponding dominant atmospheric situation when tackling the irradiation field. It is well 
Table 1

MBE (RMSE) for the simulated 10-m wind speed (m/s) over VIL and JUA weather stations and considering the RAMS, WRF and the GLDAS product. The results are presented for both daytime and night-time under distinct atmospheric conditions, as well as considering the complete period.

\begin{tabular}{|c|c|c|}
\hline & VIL & JUA \\
\hline & \multicolumn{2}{|l|}{ 10-m wind speed $(\mathrm{m} / \mathrm{s})$} \\
\hline & \multicolumn{2}{|l|}{ Western synoptic advection } \\
\hline RAMS - Day & $-0.18(0.7)$ & $0.6(0.7)$ \\
\hline RAMS - Night & $2(2)$ & $2(2)$ \\
\hline WRF - Day & $1.5(1.9)$ & $1.8(1.9)$ \\
\hline WRF - Night & $2(2)$ & $1.8(2)$ \\
\hline GLDAS - Day & $3(3)$ & $3(3)$ \\
\hline \multirow[t]{2}{*}{ GLDAS - Night } & $3(3)$ & $3(3)$ \\
\hline & \multicolumn{2}{|l|}{ Mesoscale circulation } \\
\hline RAMS - Day & $0.3(0.6)$ & $0.8(1.1)$ \\
\hline RAMS - Night & $0.9(1.2)$ & $1.2(1.4)$ \\
\hline WRF - Day & $1.6(2)$ & $1.5(1.7)$ \\
\hline WRF - Night & $2(2)$ & $1.3(1.5)$ \\
\hline GLDAS - Day & $1.7(2)$ & $2(3)$ \\
\hline \multirow[t]{2}{*}{ GLDAS - Night } & $0.3(1.4)$ & $2(2)$ \\
\hline & \multicolumn{2}{|l|}{ Eastern synoptic advection } \\
\hline RAMS - Day & $0.4(0.8)$ & $1.8(1.9)$ \\
\hline RAMS - Night & $1.5(1.6)$ & $1.5(1.7)$ \\
\hline WRF - Day & $2(3)$ & $3(3)$ \\
\hline WRF - Night & $2(3)$ & $1.8(2)$ \\
\hline GLDAS - Day & $0.9(1.2)$ & $3(3)$ \\
\hline \multirow[t]{2}{*}{ GLDAS - Night } & $0.6(1.1)$ & $1.2(1.5)$ \\
\hline & \multicolumn{2}{|c|}{ Western synoptic advection (cloudy) } \\
\hline RAMS - Day & $-0.12(1.3)$ & $0.8(1.0)$ \\
\hline RAMS - Night & $1.5(2)$ & $1.1(2)$ \\
\hline WRF - Day & $1.5(2)$ & $1.2(1.7)$ \\
\hline WRF - Night & $1.0(2)$ & $1.7(1.9)$ \\
\hline GLDAS - Day & $3(4)$ & $4(4)$ \\
\hline \multirow[t]{2}{*}{ GLDAS - Night } & $0.9(1.4)$ & $1.8(2)$ \\
\hline & \multicolumn{2}{|l|}{ All } \\
\hline RAMS & $0.7(1.4)$ & $1.2(1.5)$ \\
\hline WRF & $1.8(2)$ & $1.7(2)$ \\
\hline GLDAS & $1.9(2)$ & $3(3)$ \\
\hline
\end{tabular}

known that more incident solar radiation decreases the relative humidity field, by enhancing the warming over the corresponding area (Ruosteenoja and Räisänen, 2013). In this case, it seems that the higher humidity in WRF is linked to its decrease in the incident shortwave radiation as well.

In order to explain these differences between RAMS and WRF, we have investigated the wind field at different daytime hours over the whole area of study. We present here the results at 18 UTC (Fig. 9). We have found that the differences in both the 2-m relative humidity and the incident shortwave radiation are related to the development and progression of the Eastern flow under mesoscale circulations and the Eastern synoptic advection, as seen for different hours of the corresponding day. In the first case, the sea breeze circulation reaches inland areas using WRF, and because this is a moister flow (Fig. 9d), it enhances an increase in the relative humidity while the shortwave radiation is decreased. The same situation is produced under the Eastern synoptic advection (Fig. 9f), however in this case the sea wind is favoured by a synoptic component instead of a mesoscalar one. In any case, this wind flow is able to reach inland areas in WRF, thus increasing the water vapor mixing ratio and producing the results found. This result is supported when looking at the Western synoptic advection. In this case, this synoptic flow is well developed by RAMS and WRF, reaching areas near the coast in both cases and such differences between these simulations are not observed in terms of the incident shortwave radiation (Fig. 9a,b).

It is worth noting at this point that the formation of pollutant layers over Eastern Spain during the summer season are related to sea breeze circulations. These regional and local flows are based on diurnal time
Table 2

MBE (RMSE) for the simulated 2-m temperature $\left({ }^{\circ} \mathrm{C}\right.$ ) and 2-m relative humidity (\%) over VIL and JUA weather stations and considering the RAMS, WRF and the GLDAS product. The results are presented for both daytime and night-time under distinct atmospheric conditions, as well as considering the complete period.

\begin{tabular}{|c|c|c|c|c|}
\hline & VIL & JUA & VIL & JUA \\
\hline & \multicolumn{2}{|c|}{ 2-m temperature $\left({ }^{\circ} \mathrm{C}\right)$} & \multicolumn{2}{|c|}{ 2-m relative humidity (\%) } \\
\hline & \multicolumn{2}{|c|}{ Western synoptic advection } & & \\
\hline RAMS - Day & $-0.9(1.4)$ & $-0.6(1.1)$ & $0.019(3)$ & $-2(3)$ \\
\hline RAMS - Night & $4(4)$ & $1.9(2)$ & $-11(16)$ & $-6(8)$ \\
\hline WRF - Day & $-1.9(2)$ & $-1.9(2)$ & $3(8)$ & $-0.17(3)$ \\
\hline WRF - Night & $-1.4(2)$ & $-3(3)$ & 10 (19) & $3(6)$ \\
\hline GLDAS - Day & $0.06(0.8)$ & $-0.2(1.4)$ & $-2(5)$ & $-3(6)$ \\
\hline \multirow[t]{2}{*}{ GLDAS - Night } & $3(3)$ & $1.0(1.7)$ & $-2(5)$ & $-1.9(7)$ \\
\hline & \multicolumn{4}{|c|}{ Mesoscale circulation } \\
\hline RAMS - Day & $-0.9(1.7)$ & $-0.5(1.1)$ & $-9(12)$ & $-5(7)$ \\
\hline RAMS - Night & $1.7(3)$ & $0.4(1.1)$ & $-40(40)$ & $-4(7)$ \\
\hline WRF - Day & $-1.0(2)$ & $-0.9(1.7)$ & $-4(11)$ & $-4(9)$ \\
\hline WRF - Night & $-2(2)$ & $-2(3)$ & $7(10)$ & $5(8)$ \\
\hline GLDAS - Day & $1.3(1.9)$ & $0.2(2)$ & $-18(20)$ & $-7(11)$ \\
\hline \multirow[t]{2}{*}{ GLDAS - Night } & $2(3)$ & $1.5(2)$ & $-40(40)$ & $-1.5(7)$ \\
\hline & \multicolumn{4}{|c|}{ Eastern synoptic advection } \\
\hline RAMS - Day & $2(3)$ & $0.7(1.1)$ & $-20(20)$ & $-14(18)$ \\
\hline RAMS - Night & $5(5)$ & $-0.2(1.2)$ & $-40(40)$ & $-30(30)$ \\
\hline WRF - Day & $0.008(2)$ & $-1.3(2)$ & $-6(14)$ & $-6(8)$ \\
\hline WRF - Night & $-1.9(2)$ & $-4(4)$ & $6(7)$ & $-10(19)$ \\
\hline GLDAS - Day & $2(3)$ & $-0.4(2)$ & $-16(17)$ & $-10(14)$ \\
\hline \multirow[t]{2}{*}{ GLDAS - Night } & $3(3)$ & $-0.3(1.9)$ & $-9(12)$ & $-14(20)$ \\
\hline & \multicolumn{4}{|c|}{ Western synoptic advection (cloudy) } \\
\hline RAMS - Day & $-2(4)$ & $-0.8(1.9)$ & $2(13)$ & $0.7(6)$ \\
\hline RAMS - Night & $5(5)$ & $0.7(3)$ & $-20(30)$ & $-9(14)$ \\
\hline WRF - Day & $-1.8(2)$ & $-3(3)$ & $0.7(3)$ & $0.9(4)$ \\
\hline WRF - Night & $-1.0(1.7)$ & $-2(3)$ & $3(10)$ & $3(7)$ \\
\hline GLDAS - Day & $0.3(1.9)$ & $-0.7(1.7)$ & $-7(8)$ & $-2(4)$ \\
\hline \multirow[t]{2}{*}{ GLDAS - Night } & $3(3)$ & $-0.2(0.7)$ & $-9(9)$ & $2(7)$ \\
\hline & All & & & \\
\hline RAMS & $1.3(3)$ & $0.3(1.7)$ & $-15(20)$ & $-6(11)$ \\
\hline WRF & $-1.5(2)$ & $-2(3)$ & $3(12)$ & $-0.2(8)$ \\
\hline GLDAS & $1.4(2)$ & $0.19(1.8)$ & -12 (19) & $-4(9)$ \\
\hline
\end{tabular}

scales able to transport pollutants far inland (Millán et al., 2005). Taking into account this issue and the results shown in Fig. 9d, a proper representation of the wind field over this inland area is of significant importance for accurate air quality forecast applications. Fig. 9d shows that WRF is able to reach inland areas under breeze circulations, while the dominant Western advection over the area of study far from the coast presents a larger horizontal extension reaching areas near the coast using RAMS, while WRF blocks this circulation earlier with the entrance of the sea breeze flow. Therefore, differences in the development and progression of these circulations should be taken into account over the study area bearing in mind the production of accurate and skilful mesoscale modelling forecasts.

\subsection{How do RAMS and WRF simulations compare with other atmospheric and surface products?}

Taking advantage of the MSG-SEVIRI LST, downward shortwave (DSSF) and longwave (DSLF) radiation magnitudes, we present in Fig. 10 a comparison of these magnitudes with those simulated by RAMS and WRF. Considering RAMS (Fig. 10a), there is a general overestimation of both the night and daytime LST temperatures provided by SEVIRI-LST. However, WRF simulates lower temperatures than SEVIRI (Fig. 10b). A look at the comparison of the LST provided by SEVIRI, RAMS, WRF and GLDAS over VIL and JUA (Fig. 11a,b) reflects that GLDAS have a low diurnal temperature range in terms of the LST variable in comparison to WRF and RAMS. The LST differences between RAMS and SEVIRI are notably reduced during the day, capturing the 
Table 3

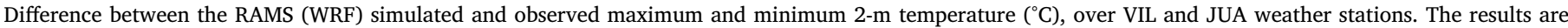
presented for each day within the simulation period, as well as considering the mean of the complete period.

\begin{tabular}{|c|c|c|c|c|}
\hline Day & VIL - T. Maximum & JUA - T. Maximum & VIL - T. minimum & JUA - T. Minimum \\
\hline 06/07/2011 & $-0.7(-1.2)$ & $-0.5(-1.6)$ & $3(-4)$ & $3(-3)$ \\
\hline 07/07/2011 & $0.08(-1.4)$ & $-0.03(-1.8)$ & $6(-0.12)$ & $0.4(-5)$ \\
\hline 08/07/2011 & $0.03(-0.7)$ & $-0.3(-1.3)$ & $5(-0.7)$ & $3(-3)$ \\
\hline 09/07/2011 & $-0.15(-0.02)$ & $0.4(-1.6)$ & $-2(-1.4)$ & $1.8(-1.2)$ \\
\hline $10 / 07 / 2011$ & $-0.4(-0.11)$ & $0.05(-1.2)$ & $0.4(-3)$ & $-0.8(-2)$ \\
\hline $11 / 07 / 2011$ & $4(3)$ & $-0.2(-1.9)$ & $2(-3)$ & $-0.6(-4)$ \\
\hline $12 / 07 / 2011$ & $-1.3(-2)$ & $-0.18(-3)$ & $5(-1.2)$ & $1.8(-0.7)$ \\
\hline Mean & $0.2(-0.3)$ & $-0.11(-1.8)$ & $3(-1.9)$ & $1.2(-3)$ \\
\hline
\end{tabular}

Table 4

MBE (RMSE) for the RAMS and WRF simulated downward shortwave radiation $\left(\mathrm{W} \mathrm{m}^{-2}\right)$ over VIL and JUA weather stations, considering the SEVIRI and GLDAS products as well. The results are presented under distinct atmospheric conditions, as well as considering the complete period.

\begin{tabular}{lll} 
& VIL & JUA \\
\hline & Incident solar radiation $\left(\mathrm{W} \mathrm{m}^{-2}\right)$ & \\
& Western synoptic advection & \\
RAMS & $5(70)$ & $-5(10)$ \\
WRF & $0.8(70)$ & $-9(15)$ \\
GLDAS & $-3(40)$ & $-9(40)$ \\
SEVIRI & $-11(30)$ & $-17(50)$ \\
& Mesoscale circulation & \\
RAMS & $15(60)$ & $-5(11)$ \\
WRF & $4(80)$ & $-11(20)$ \\
GLDAS & $6(30)$ & $-5(40)$ \\
SEVIRI & $-0.2(17)$ & $-20(60)$ \\
& Eastern synoptic advection & \\
RAMS & $30(90)$ & $8(16)$ \\
WRF & $9(110)$ & $3(15)$ \\
GLDAS & $30(60)$ & $7(40)$ \\
SEVIRI & $13(40)$ & $-20(80)$ \\
& Western synoptic advection (cloudy) & $-80(200)$ \\
RAMS & $-110(400)$ & $-80(190)$ \\
WRF & $-70(140)$ & $-50(130)$ \\
GLDAS & $-50(170)$ & $-10(60)$ \\
SEVIRI & $-40(90)$ & $-13(80)$ \\
RAMS & All & $-18(60)$ \\
WRF & $-4(150)$ & \\
GLDAS & $-8(90)$ & \\
SEVIRI & $-9(80)$ & \\
\hline & & \\
& & \\
& &
\end{tabular}

high temperatures provided by SEVIRI. If we contrast GLDAS with SEVIRI, notable differences are found between these two products. Besides, it is worth noting at this point the similitude between GLDAS and WRF during the day in comparison to RAMS. Considering the WRF model, a general trend towards low daytime skin temperatures is obtained, compared to RAMS and SEVIRI (Fig. 11a,b). This temperature bias seems to point to the corresponding Noah-MP LSM used in the WRF simulations. Additionally, the same temperature bias is obtained at night-time using WRF, but it is remarkably reduced compared to the one found during the day. In the case of the LEAF3 model used in the RAMS simulations, a better representation is found in terms of the daytime skin temperatures. However, the minimum temperatures are reached too slowly using this model. The surface cooling simulated by LEAF3 at night-time is not as strong as observed and as simulated by Noah-MP LSM.

On the other hand, SEVIRI-DSLF produces in general higher values than WRF in the downward longwave radiation at night-time (Fig. 10d). Considering this magnitude, RAMS does not produce the higher values simulated by WRF (Fig. 10c,d), while GLDAS provides very similar values to WRF, even though higher than those simulated by RAMS (Fig. 7c,d). Regarding this magnitude simulated by RAMS and
WRF, Steeneveld et al. (2011) found that WRF produced larger incoming longwave radiation values than RAMS over Cabauw site (Netherlands) as well, more adjusted to the observations, but still underestimated with notable differences. This study pointed out the relative difficulty of both models to reproduce the longwave downwelling flux, pointing out to a deficiency in the radiation schemes independently implemented in these mesoscale models as the more possible reason for the model biases in this magnitude. In the case of WRF, a recent study by Kalverla et al. (2016) used three different radiation parameterizations in order to try to improve the overall model performance, but similar results were found, and not a significant improvement appeared in the simulated incoming longwave radiation by changing the radiation scheme.

If we compare the downward shortwave radiation simulated by RAMS and WRF with the SEVIRI-DSSF product, a lower correlation coefficient is obtained for RAMS in comparison to WRF (Fig. 10e), while WRF clearly produces higher values in this magnitude than SEVIRI (Fig. 10f). The downward shortwave radiation values highlighted in Fig. 10e,f are due to the cloudy conditions observed on 12 July. Although the mesoscale modelling results show higher values after midday in comparison to the remote sensing data, the tendency is the opposite before noon (not shown), following the outcomes presented in Fig. 7a,b over VIL and JUA, respectively.

Considering the $10-\mathrm{m}$ wind speed provided by GLDAS, Fig. 3 shows that this product reproduces well the observations over the area of study. Besides, it presents a similar behaviour to WRF in spite that GLDAS is configured with a lower horizontal resolution than WRF. Fig. 3 highlights more differences between GLDAS and RAMS. These results should not be surprising as GLDAS is configured using Noah LSM. Even though working with this lower horizontal resolution, GLDAS is still able to reproduce the main features observed for the whole simulation period, especially taking into account the daytime cycle. In contrast, it seems that GLDAS shows more difficulties at nighttime, leading a more windy field than that simulated by RAMS and WRF (Table 1). If we focus on the air temperature provided by the GLDAS product (Fig. 4), maximum temperatures are properly captured in general, with a trend to slightly underestimate the observations over JUA (Table 2). However, more differences are obtained at night-time, with a general overestimation of the air temperature, especially over VIL.

Finally, another important magnitude for those applications related to surface properties is the soil moisture content. Fig. 11c,d show this magnitude simulated by RAMS and WRF in relation to that provided by GLDAS over VIL and JUA. Similar results are found over these two weather stations, with RAMS producing soil moisture contents close to WRF, especially over VIL.

\section{Summary and conclusions}

The current study evaluates the ability of two state-of-the-art atmospheric models, RAMS and WRF, to forecast different surface and near-surface variables over a region in Eastern Spain and under distinct 
atmospheric conditions typical of the Western Mediterranean coast. In order to perform a comparative assessment of the models' results, in addition to available in-situ observations, we have used remote sensing data derived from the MSG-SEVIRI sensor and the uncoupled LSM GLDAS.

In terms of the wind field, the following results have been found: 1) The wind field is well captured by both models, especially under mesoscale circulations, even though they tend to overestimate the observed night-time winds. 2) A different degree of agreement is found in the simulated wind speed under distinct atmospheric conditions. 3) In general, WRF is more windy than RAMS under all atmospheric conditions at daytime. 4) The results provided by GLDAS in terms of the wind speed are rather similar to those simulated by WRF during the day.

Considering the temperature field: 1) It is well captured by RAMS at daytime, while WRF shows a cold bias during the day. 2) RAMS is in general warmer than WRF both during the day and at night-time. 3) The largest differences between satellite data and mesoscale simulations during the day are produced using the WRF configuration. 4) WRF presents a better agreement with the SEVIRI-LST product than RAMS at night, even though simulating colder LST than SEVIRI.

In relation to the radiation terms: 1) Similar results are obtained for the downward shortwave radiation for RAMS and WRF. 2) WRF simulates a larger downward longwave radiation field than RAMS, especially at daytime. 3) There is a general underestimation of the simulated incoming longwave radiation.

Finally, a question that arises when comparing RAMS and WRF in areas nearer the coast, such as VIL, is the importance of a reliable representation of the sea-breeze front. In the current study, it has been shown, considering Eastern wind circulations, that WRF is able to reach inland areas than RAMS, leading to a transport of moisture far inland, and influencing other physical magnitudes, such as the temperature field. Therefore, this issue should be investigated more in depth in order to better evaluate the performance of these mesoscale models in the forecast of sea to land atmospheric flows, both at the mesoscale or forced by synoptic atmospheric conditions.

To conclude, the current study is focused on the analysis of distinct atmospheric conditions typical of the study area and developed within a 7-days simulation period. The key results found here encourages us to continue developing further research in this field. In this regard, more in-depth analysis should be performed, by means of increasing the simulation period so as to have a larger database of these typical atmospheric situations. It is the plan of the authors to continue the current study in order to provide more general and final conclusions.

\section{Acknowledgement}

This work has been funded by the Regional Government of Valencia through the project PROMETEOII/2014/086 and by the Spanish Ministerio de Economía y Competitividad and the European Regional Development Fund (FEDER) through the project CGL2015-64268-R (MINECO/FEDER,UE). We would like to thank the Spanish Ministry of Agriculture, Food and Environment for making surface observations available through the SIAR system. NCEP is acknowledged for providing the FNL analysis data for RAMS and WRF initialization. National Centers for Environmental Prediction/National Weather Service/ NOAA/U.S. Department of Commerce (2000): NCEP FNL Operational Model Global Tropospheric Analyses, continuing from July 1999. Research Data Archive at the National Center for Atmospheric Research, Computational and Information Systems Laboratory. Dataset. http://rda.ucar.edu/datasets/ds083.2. Accessed 25 August 2014. The GLDAS data used in this study were acquired as part of the mission of NASA's Earth Science Division and archived and distributed by the Goddard Earth Sciences (GES) Data and Information Services Center (DISC) are acknowledged by disseminating the GLDAS data. Land Surface Analysis Satellite Application Facility (LSA SAF) are acknowledged as well for providing the satellite data for RAMS and WRF comparison. Finally, we thank the two anonymous reviewers for their constructive feedback on the manuscript.

\section{References}

Avolio, E., Torcasio, R.C., Lo Feudo, T., Calidonna, C.R., Contini, D., Federico, S., 2016 Improvement of solar and wind forecasting in southern Italy through a multi-model approach: preliminary results. Adv. Sci. Res. 13, 69-73. https://doi.org/10.5194/asr13-69-2016.

Avolio, E., Federico, S., Miglietta, M.M., Lo Feudo, T., Calidonna, C.R., Sempreviva, A.M., 2017. Sensitivity analysis of WRF model PBL schemes in simulating boundary-layer variables in southern Italy: an experimental campaign. Atmos. Res. 192, 58-71. https://doi.org/10.1016/j.atmosres.2017.04.003.

Banks, R.F., Baldasano, J.M., 2016. Impact of WRF model PBL schemes on air quality simulations over Catalonia. Spain. Sci. Total Environ. 572, 98-113. https://doi.org/ 10.1016/j.scitotenv.2016.07.167.

Banks, R.F., Tiana-Alsina, J., Baldasano, J.M., Rocadenbosch, F., Papayannis, A., Solomos, S., Tzanis, C.G., 2016. Sensitivity of boundary-layer variables to PBL schemes in the WRF model based on surface meteorological observations, lidar, and radiosondes during the HygrA-CD campaign. Atmos. Res. 176, 185-201. https://doi.org/10. 1016/j.atmosres.2016.02.024.

Borge, R., Alexandrov, V., del Vas, J.J., Lumbreras, J., Rodríguez, E., 2008. A comprehensive sensitivity analysis of the WRF model for air quality applications over the Iberian peninsula. Atmos. Environ. 42, 8560-8574. https://doi.org/10.1016/j atmosenv.2008.08.032.

Brisson, A., Leborgne, P., Marsouin, A., 1999. Development of Algorithms for Surface Solar Irradiance Retrieval at O\&SI SAF Low and Mid Latitude. Météo-France/CMS, Lannion.

Caselles, V., Valor, E., Coll, C., Rubio, E., 1997. Thermal band selection for the PRISM instrument 1.Analysis of emissivity-temperature separation algorithms. J. Geophys. Res. 102 (D10), 11145-11164. https://doi.org/10.1029/97JD00344.

Castro, C., Cheng, W., Beltrán, A., Marshall Jr., C., Pielke Sr., R., Cotton, W., 2002. The incorporation of the Kain-Fritsch cumulus parameterization scheme in RAMS with a terrain-adjusted trigger function. In: Fifth RAMS Users Workshop, Santorini Island, Greece, 29 September-October 3.

Chen, C., Cotton, W.R., 1983. A one-dimensional simulation of the stratocumulus-capped mixed layer. Boundary-Layer Meteorol. 25, 289-321. https://doi.org/10.1007/ BF00119541.

Chen, F., Dudhia, J., 2001a. Coupling an advanced land surface-hydrology model with the Penn State-NCAR MM5 modeling system. Part I: model implementation and sensitivity. Mon. Wea. Rev. 129, 569-585. https://doi.org/10.1175/15200493(2001)129<0569:CAALSH > 2.0.CO;2.

Chen, F., Dudhia, J., 2001b. Coupling an advanced land surface-hydrology model with the Penn State-NCAR MM5 modeling system. Part II: preliminary model validation. Mon. Wea. Rev. 129, 587-604. https://doi.org/10.1175/1520-0493(2001) $129<0587$ :CAALSH > 2.0.CO;2.

Cotton, W.R., Pielke, R.A.S., Walko, R.L., Liston, G.E., Tremback, C.J., Jiang, H., McAnelly, R.L., Harrington, J.Y., Nicholls, M.E., Carrio, G.G., McFadden, J.P., 2003 RAMS 2001: current status and future directions. Meteorog. Atmos. Phys. 82 (1-4), 5-29. https://doi.org/10.1007/s00703-001-0584-9.

Dillon, M.E., Collini, E.A., Ferreira, L.J., 2016. Sensitivity of WRF short-term forecasts to different soil moisture initializations from the GLDAS database over South America in March 2009. Atmos. Res. 167, 196-207. https://doi.org/10.1016/j.atmosres.2015. 07.022 .

Draxl, C., Hahmann, A.N., Peña, A., Giebel, G., 2014. Evaluating winds and vertical wind shear from Weather Research and Forecasting model forecasts using seven planetary boundary layer schemes. Wind Energ. 17, 39-55. https://doi.org/10.1002/we.1555.

Dudhia, J., 1989. Numerical study of convection observed during the winter monsoon experiment using a mesoscale two-dimensional model. J. Atmos. Sci. 46, 3077-3107. https://doi.org/10.1175/1520-0469(1989)046 < 3077:NSOCOD > 2.0.CO;2.

Ek, M.B., Mitchell, K.E., Lin, Y., Rogers, E., Grunmann, P., Koren, V., Gayno, G., Tarpley, J.D., 2003. Implementation of Noah land surface model advances in the National Centers for environmental prediction operational mesoscale eta model. J. Geophys. Res. 108 (D22), 8851. https://doi.org/10.1029/2002JD003296.

Federico, S., Torcasio, R.C., Sanò, P., Casella, D., Campanelli, M., Meirink, J.F., Wang, P., Vergari, S., Diémoz, H., Dietrich, S., 2017. Comparison of hourly surface downwelling solar radiation estimated from MSG-SEVIRI and forecast by the RAMS model with pyranometers over Italy. Atmos. Meas. Tech. 10, 2337-2352. https://doi.org/ 10.5194/amt-10-2337-2017.

Giannaros, T.M., Melas, D., Ziomas, I., 2017. Performance evaluation of the weather research and forecasting (WRF) model for assessing wind resource in Greece. Renew. Energy 102, 190-198. https://doi.org/10.1016/j.renene.2016.10.033.

Gómez, I., Estrela, M.J., 2010. Design and development of a java-based graphical user interface to monitor/control a meteorological real-time forecasting system. Comput. Geosci. 36, 1345-1354. https://doi.org/10.1016/j.cageo.2010.05.005.

Gómez, I., Estrela, M.J., Caselles, V., 2014a. Operational forecasting of daily summer maximum and minimum temperatures in the Valencia region. Nat. Hazards 70 (2), 1055-1076. https://doi.org/10.1007/s11069-013-0861-1.

Gómez, I., Caselles, V., Estrela, M.J., 2014b. Real-time weather forecasting in the Western Mediterranean Basin: an application of the RAMS model. Atmos. Res. 139, 71-89. https://doi.org/10.1016/j.atmosres.2014.01.011.

Gómez, I., Caselles, V., Estrela, M.J., Niclòs, R., 2014c. RAMS-forecasts comparison of typical summer atmospheric conditions over the Western Mediterranean coast. Atmos. Res. 145-146, 130-151. https://doi.org/10.1016/j.atmosres.2014.03.018. 
Gómez, I., Estrela, M.J., Caselles, V., 2015a. Verification of the RAMS-based operational weather forecast system in the Valencia Region: a seasonal comparison. Nat. Hazards 75 (2), 1941-1958. https://doi.org/10.1007/s11069-014-1408-9.

Gómez, I., Caselles, V., Estrela, M.J., 2015b. Impacts of soil moisture content on simulated mesoscale circulations during the summer over eastern Spain. Atmos. Res. 164-165, 9-26. https://doi.org/10.1016/j.atmosres.2015.04.015.

Gómez, I., Caselles, V., Estrela, M.J., 2016a. Seasonal characterization of solar radiation estimates obtained from a MSG-SEVIRI-derived dataset and a RAMS-based operational forecasting system over the western Mediterranean coast. Remote Sens. 8, 46. https://doi.org/10.3390/rs8010046.

Gómez, I., Ronda, R.J., Caselles, V., Estrela, M.J., 2016b. Implementation of non-local boundary layer schemes in the regional atmospheric modeling system and its impact on simulated mesoscale circulations. Atmos. Res. 180, 24-41. https://doi.org/10. 1016/j.atmosres.2016.04.020.

Gómez, I., Caselles, V., Estrela, M.J., Niclòs, R., 2016c. Impact of initial soil temperature derived from remote sensing and numerical weather prediction datasets on the simulation of extreme heat events. Remote Sens. 8, 589. https://doi.org/10.3390/ rs8070589.

Gómez, I., Caselles, V., Estrela, M.J., Sánchez, J.M., Rubio, E., 2018. Simulation of surface energy fluxes and meteorological variables using the regional atmospheric modeling system (RAMS): evaluating the impact of land-atmosphere coupling on short-term forecasts. Agric. For. Meteorol. 249, 319-334. https://doi.org/10.1016/j.agrformet 2017.10.027.

Hariprasad, K.B.R.R., Srinivas, C.V., Bagavath Singh, A., Vijaya Bhaskara Rao, S., Baskaran, R., Venkatraman, B., 2014. Numerical simulation and intercomparison of boundary layer structure with different PBL schemes in WRF using experimental observations at a tropical site. Atmos. Res. 145-146, 27-44. https://doi.org/10.1016/ j.atmosres.2014.03.023

Hong, S.-Y., Lim, J.-O.J., 2006. The WRF single-moment 6-class microphysics scheme (WSM6). J. Korean Meteor. Soc 42 (2), 129-151.

Hong, S., Noh, Y., Dudhia, J., 2006. A new vertical diffusion package with an explicit treatment of entrainment processes. Mon. Wea. Rev. 134 (9), 2318-2341. https:// doi.org/10.1175/MWR3199.1.

Hong, S., Lakshmi, V., Small, E.E., Chen, F., Tewari, M., Manning, K.W., 2009. Effects of vegetation and soil moisture on the simulated land surface processes from the coupled WRF/Noah model. J. Geophys. Res. 114, D18118. https://doi.org/10.1029/ 2008JD011249.

Hu, X.-M., Nielsen-Gammon, J.W., Zhang, F., 2010. Evaluation of three planetary boundary layer schemes in the WRF model. J. Appl. Meteor. Climatol. 49 (9), 1831-1844. https://doi.org/10.1175/2010JAMC2432.1.

Kain, J.S., 2004. The Kain-Fritsch convective parameterization: an update. J. Appl Meteorol. 43, 170-181. https://doi.org/10.1175/1520-0450(2004) $043<0170$ :TKCPAU > 2.0.CO;2.

Kalverla, P., Duine, G., Steeneveld, G., Hedde, T., 2016. Evaluation of the weather research and forecasting model in the Durance Valley complex terrain during the KASCADE field campaign. J. Appl. Meteor. Climatol. 55, 861-882. https://doi.org/ 10.1175/JAMC-D-15-0258.1.

Kioutsioukis, I., de Meij, A., Jakobs, H., Katragkou, E., Vinuesa, J.-F., Kazantzidis, A., 2016. High resolution WRF ensemble forecasting for irrigation: multi-variable evaluation. Atmos. Res. 167, 156-174. https://doi.org/10.1016/j.atmosres.2015.07. 015.

Lara-Fanego, V., Ruiz-Arias, J.A., Pozo-Vázquez, D., Santos-Alamillos, F.J., TovarPecador, J., 2012. Evaluation of the WRF model solar irradiance forecasts in Andalusia (southern Spain). Sol. Energy 86, 2200-2217. https://doi.org/10.1016/j. solener. 2011.02.014.

Lara-Fanego, V., Ruiz-Arias, J.A., Pozo-Vazquez, D., Santos-Alamillos, F.J., Tovar-Lin, T. Cheng, F., 2016. Impact of soil moisture initialization and soil texture on simulated land-atmosphere interaction in Taiwan. J. Hydrometeorol. 17, 1337-1355. https:// doi.org/10.1175/JHM-D-15-0024.1.

Lompar, M., Ćuric, M., Romanic, D., 2017. Simulation of a severe convective storm using a numerical model with explicitly incorporated aerosols. Atmos. Res. 194, 164-177. https://doi.org/10.1016/j.atmosres.2017.04.037.

Lompar, M., Ćuric, M., Romanic, D., 2018. Implementation of a gust front head collapse scheme in the WRF numerical model. Atmos. Res. 203, 231-245. https://doi.org/10. 1016/j.atmosres.2017.12.018.

Millán, M.M., Estrela, M.J., Sanz, M.J., Mantilla, E., Martín, M., Pastor, F., Salvador, R., Vallejo, V.R., Alonso, L., Gangoiti, G., Ilardia, J.L., Navazo, M., Albizuri, A., Artiñano, B., Ciccioli, P., Kallos, G., Carvalho, R.A., Andrés, D., Hoff, A., Werhahn, J., Seufert,
G., Versino, B., 2005. Climatic feedbacks and desertification: the Mediterranean model. J. Clim. 18, 684-701. https://doi.org/10.1175/JCLI-3283.1.

Mlawer, E., Taubman, S., Brown, P., Iacono, M., Clough, S., 1997. Radiative transfer for inhomogeneous atmospheres: RRTM, a validated correlated-k model for the long wave. J. Geophys. Res. 102 (D14), 16663-16682. https://doi.org/10.1029/ 97JD00237.

Niu, G.-Y., Yang, Z.-L., Mitchell, K.E., Chen, F., Ek, M.B., Barlage, M., Kumar, A., Manning, K., Niyogi, D., Rosero, E., Tewari, M., Xia, Y., 2011. The community Noah land surface model with multiparameterization options (Noah-MP): 1. Model description and evaluation with local-scale measurements. J. Geophys. Res. 116 D12109. https://doi.org/10.1029/2010JD015139.

Pielke Sr., R.A., 2013. Mesoscale meteorological modeling, 3rd Edition. Academic Press, San Diego, CA (760 pp).

Prata, A.J., 1996. A new long-wave formula for estimating downward clear-sky radiation at the surface. Q. J. Roy. Meteor. Soc. 122, 1121-1151. https://doi.org/10.1002/qj. 49712253306

Rodell, M., Houser, P.R., Jambor, U., Gottschalck, J., Mitchell, K., Meng, C.J., Arsenault, K., Cosgrove, B., Radakovich, J., Bosilovich, M., Entin, J.K., Walker, J.P., Lohmann, D., Toll, D., 2004. The global land data assimilation system. Bull. Am. Meteorol. Soc. 85, 381-394. https://doi.org/10.1175/BAMS-85-3-381.

Ruosteenoja, K., Räisänen, P., 2013. Seasonal changes in solar radiation and relative humidity in Europe in response to global warming. J. Clim. 26, 2467-2481. https:// doi.org/10.1175/JCLI-D-12-00007.1.

Santanello, J.A., Kumar, S.V., Peters-Lidard, C.D., Lawston, P.M., 2016. Impact of soil moisture assimilation on land surface model Spinup and coupled land-atmospher prediction. J. Hydrometeorol. 17, 517-540. https://doi.org/10.1175/JHM-D-150072.1 .

Santos-Alamillos, F.J., Pozo-Vázquez, D., Ruiz-Arias, J.A., Tovar-Pescador, J., 2015. Influence of land-use misrepresentation on the accuracy of WRF wind estimates: evaluation of GLCC and CORINE land-use maps in southern Spain. Atmos. Res. 157, 17-28. https://doi.org/10.1016/j.atmosres.2015.01.006.

Skamarock, W.C., Klemp, J.B., Dudhia, J., Gill, D.O., Barker, D.M., Duda, M.G., Huang, X.Y., Wang, W., Powers, J.G., 2008. A description of the advanced research WRF version 3. In: NCAR Technical Note, NCAR/TN-475 + STR. Mesoscale and Microscale Meteorology Division, National Center for Atmospheric Research, Boulder, CO, USA.

Steeneveld, G.J., Tolk, L.F., Moene, A.F., Hartogensis, O.K., Peters, W., Holtslag, A.A.M., 2011. Confronting the WRF and RAMS mesoscale models with innovative observations in the Netherlands: evaluating the boundary layer heat budget. J. Geophys. Res. Atmos. 116 (D23), D23114. https://doi.org/10.1029/2011JD016303.

Tiriolo, L., Torcasio, R.C., Montesanti, S., Federico, S., 2015. Verification of a real time weather forecasting system in Southern Italy. Adv. Meteorol. 2015 Article ID 758250 14 pages. https://doi.org/10.1155/2015/758250.

Tolk, L.F., Peters, W., Meesters, A.G.C.A., Groenendijk, M., Vermeulen, A.T., Steeneveld, G.J., Dolman, A.J., 2009. Modelling regional scale surface fluxes, meteorology and $\mathrm{CO}_{2}$ mixing ratios for the Cabauw tower in the Netherlands. Biogeosciences 6 (2265-2280), 2009. https://doi.org/10.5194/bg-6-2265-2009.

Trigo, I.F., Monteiro, I.T., Olesen, F., Kabsch, E., 2008. An assessment of remotely sensed land surface temperature. J. Geophys. Res. 113, D17108. https://doi.org/10.1029/ 2008JD010035.

Walko, R.L., Cotton, W.R., Meyers, M.P., Harrington, J.Y., 1995. New RAMS cloud microphysics parameterization. Part I: The single-moment scheme. Atmos. Res. 38, 29-62. https://doi.org/10.1016/0169-8095(94)00087-T.

Walko, R.L., Band, L.E., Baron, J., Kittel, T.G.F., Lammers, R., Lee, T.J., Ojima, D., Pielke, R.A., Taylor, C., Tague, C., Tremback, C.J., Vidale, P.L., 2000. Coupled atmosphericbiophysics-hydrology models for environmental modeling. J. Appl. Meteorol. 39, 931-944. https://doi.org/10.1175/1520-0450(2000)039<0931:CABHMF $>2.0$. $\mathrm{CO} ; 2$.

Xie, B., Fung, J.C.H., Chan, A., Lau, A., 2012. Evaluation of nonlocal and local planetary boundary layer schemes in the WRF model. J. Geophys. Res. 117, D12103. https:// doi.org/10.1029/2011JD017080.

Yang, Z.-L., Niu, G.-Y., Mitchell, K.E., Chen, F., Ek, M.B., Barlage, M., Longuevergne, L., Manning, K., Niyogi, D., Tewari, M., Xia, Y., 2011. The community Noah land surface model with multiparameterization options (Noah-MP): 2. Evaluation over global river basins. J. Geophys. Res. 116, D12110. https://doi.org/10.1029/ 2010JD015140.

Zhang, H., Pu, Z., Zhang, X., 2013. Examination of errors in near-surface temperature and Wind from WRF numerical simulations in regions of complex terrain. Wea. Forecasting 28, 893-914. https://doi.org/10.1175/WAF-D-12-00109.1. 